\title{
Selection of Ionic Liquid Solvents for Chemical Separations Based on the Abraham Model
}

\author{
William E. Acree, Jr. ${ }^{1}$, Laura M. Grubbs ${ }^{1}$ and Michael H. Abraham² \\ ${ }^{1}$ University of North Texas, \\ 2 University College London \\ 1 United States \\ 2United Kingdom
}

\section{Introduction}

Room temperature ionic liquids (RTILs) have generated considerable interest in the past decade because of their unique physical and chemical properties. Each year the number of published applications employing RTILs as solvent media has increased. New generation RTILs are a popular solvent choice for manufacturing applications involving nano-materials and new pharmaceutical drug molecules, as high-temperature lubricants for metal-to-metal contacts, as reservoirs for the controlled release of drug molecules in pharmaceutical formulations, as chromatographic stationary phases for gas chromatographic separations, as gas absorption agents, and as an extraction solvent system for the removal of aromatic nitrogen and sulfur compounds from coal and petroleum feedstocks. RTILs are usually made by combining a poorly coordinating cation and anion to give a highly polar ionic liquid. Ionic liquids are often immiscible with supercritical carbon dioxide, saturated linear hydrocarbons and several acyclic organic solvents. Liquid immiscibility makes RTILs ideally suited for synthetic methods involving biphasic catalysis.

Currently synthetic procedures are available for preparing more than 300 different ionic liquids (ILs), including dication and tricationic bis/tris-imidazolium-based ILs, polymeric ionic liquids (PILs), and chirial ionic liquids. Methods have also been developed for introducing polar functional groups to the end of an alkyl $\mathrm{CH}_{2}$-chain. The overall physical and solubilizing properties of ILs result from the composite properties of the cation and anion. The anion generally controls the extent to which the RTIL is miscible with water. The cation of an IL is usually a bulky organic structure (alkylimidazolium, alkylpyridinium, alkylpyrrolidinium, tetraalkylphosphonium and tetraalkylammonium - See Figure 1 for molecular structures) with low molecular symmetry. Cation type and size/symmetry affect the IL's melting point temperature. The melting point temperature is important because it represents the lower limit of liquidity, and when combined with thermal stability, it defines the temperature interval over which the IL can be used as a liquid solvent. Experimental studies have found that ILs having dications have a greater temperature interval of thermal stability than their monocation counterparts.

The solubilizing properties of an IL can be modified by changing the cation-anion combination. Our understanding of the properties of ILs has improved considerably in recent years, to the point where we can now begin to suggest possible IL solvents for 
achieving a desired chemical separation. One specific application involves the addition of an IL (as an entrainer) to an azeotropic system whose components are not separable by ordinary distillation methods. The added ionic liquid entrainer interacts with the components of the azeotropic system, and alters the component's relative volatilities. Verma and Banerjee (2010) examined the various IL combinations involving 10 cations (imidazolium, pyridinium and quinolium) and 24 anions as entrainers for water + ethanol, water + 2-propanol and water + tetrahydrofuran systems with the 1,3-dimethylimidazolium cation, $\left[\mathrm{M}_{2} \mathrm{Im}\right]^{+}$, in combination with the acetate, $[\mathrm{Ac}]^{-}$, chloride $[\mathrm{Cl}]^{-}$, and bromide, $[\mathrm{Br}]^{-}$, anions giving the highest relative volatility. Chemicals in azeotropic mixtures have been separated also by liquid-liquid extraction using an IL solvent as schematically illustrated in Figure 2. Pereiro et al. (2010) explored 1-ethyl-3-methylimidazolium ethyl sulfate IL as an extraction solvent for the removal of ethanol from ethanol + heptane and ethanol + hexane azeotropic mixtures. Ionic liquid entrainers have been used successfully in the separation of alkanes from alkenes (propane versus propene (Mokrushina et al., 2010), hexane versus 1hexene (Lei et. al., 2006), alkanes from aromatic compounds (cyclohexane versus benzene (Zhu et al. 2004), and of acetylene from ethylene (Palgunadi et al., 2010). Recent review articles (Soukup-Hein et al., 2009; Lei et al. 2003; Pandey, 2006; Poole and Poole, 2010) have discussed the advances that have been made in chemical separations using IL solvents.

Gas-liquid chromatography (glc) and high-performance liquid chromatography (hplc) afford convenient methods for separating organic compounds in mixtures prior to quantification of mixture composition. The IL can serve as the stationary phase, or in the case of hplc can be an organic modifier added to the mobile phase to affect the solute's partitioning characteristics. The solute partitions between the stationary and mobile phases as it passes through the chromatographic column. The elution time is governed by the partition coefficient, which is defined as

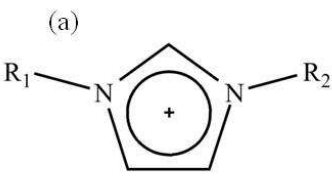

(d)

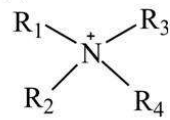

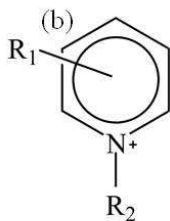

(e)<smiles>[R][SH]([R])[R]</smiles>

(c)<smiles>[R][N+]1([R])CCCC1</smiles>

(f)<smiles>[R][PH]([R])([R])[R]</smiles>

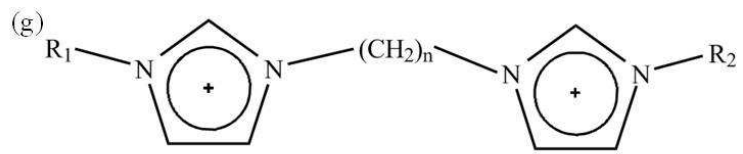

Fig. 1. Molecular Structures for 1,3-disubstituted imidazolium (a), substituted pyridinium (b), substituted pyrrolidinium (c), tetraalkylammonium (d), trialkylsulfonium (e), tetraalkylphosphonium (f), and bis(1,3-disubstituted imidazolium) cations (g). The substitutes are alkyl or functionalized alkyl chains and are denoted as $R_{1}, R_{2}, R_{3}$ and $R_{4}$. 


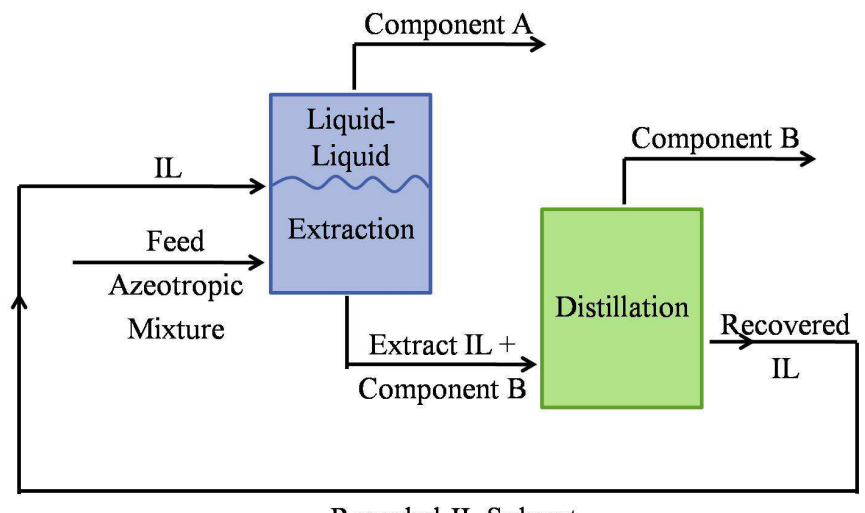

Recycled IL Solvent

Fig. 2. Process for the separation of Component A and Component B from an azeotropic mixture using an IL solvent

$$
P=\frac{C_{\text {solute, } \text { mobile phase }}}{C_{\text {solute, } \text {,tationary phase }}}
$$

the ratio of the molar concentration of the solute in the respective mobile and stationary phases. The partition coefficient is a relative measure of the affinity that the solute exhibits for each phase. Each solute is expected to interact differently with the two phases.

Numerous publications have reported using IL solvents in conjunction with chromatographic analyses (Soukup-hein et al., 2009; Pandey, 2006; Poole and Poole, 2010). For example, Seely et al. (2008) studied chemical separations of complex mixtures on a twodimensional gas chromatographic column. The system consisted of a trihexyl(tetradecyl)phoshonium bis(trifluoromethane)-sulfonamide IL primary column coupled to a (5\% diphenyl $+95 \%$ dimethyl)polysiloxane secondary column. The authors found that the two-dimensional system separated the major components of diesel fuel into three narrow bands: saturated hydrocarbons, monoaromatics and diaromatics. Yao et al. (2009) employed various ILs containing the tris(pentafluoroethyl)trifluorophosphate anion. $[\mathrm{FAP}]$-, as extraction solvents for direct immersion single drop micro-extraction studies prior to hplc analysis. Ionic liquids tend to form larger and more stable microdroplets than do the more traditional organic solvents, and their elution time in hplc is very short and does not affect the chemical separation. The largest enrichment factors for compounds with high molar masses and fused rings were obtained with trihexyl(tetradecyl)phoshonium bis(pentafluoroethyl)trifluorophosphate. 1-Methyl-3-hexyl-imidazolium [FAP] gave the better results for the smaller molecules studied.

Headspace micro-extraction methods (Zhao et al. 2008 and 2009; Aguilera-Herrador et al. 2008; Liu et al., 2003) have been developed for the partitioning of volatile and semivolatile compounds into an exposed IL drop. In the micro-extraction setup depicted in Figure 3 a syringe needle is inserted through the sample vial septum. The syringe needle is slowly depressed to expose the IL microdrop to the vapor above the aqueous sample. The volatile solutes then partition into the ionic liquid solvent from the vapor phase. After a predetermined equilibration time, the microdrop is retracted back into the syringe needle. 
The syringe is removed and inserted into the injection port of a gas chromatograph. The syringe plunger is depressed in order to expose, but not inject, the IL microdrop. The volatile solutes thermally desorb from the IL drop at the higher temperature. Solute concentrations are quantified by gas chromatographic analysis.

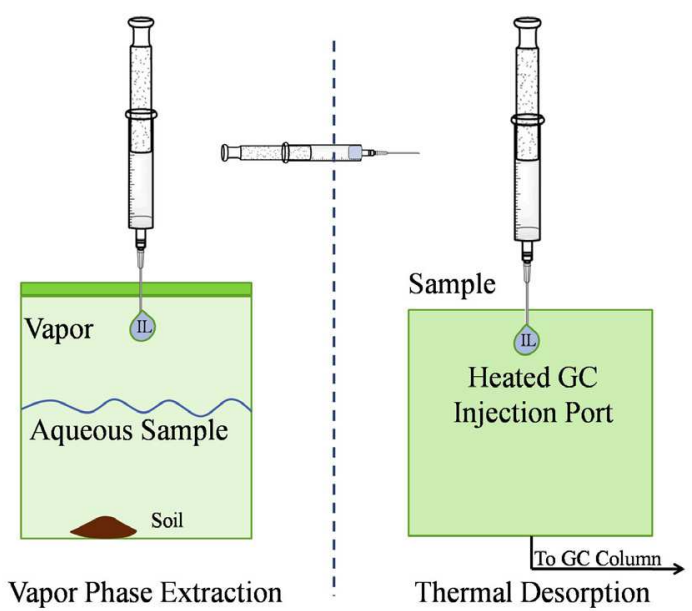

Fig. 3. Simple headspace ionic liquid-based microextraction setup for extracting volatile organic compounds from a contaminated soil sample. Organic contaminates on the soil dissolve into the aqueous phase. The organic vapors above the aqueous solution partition into the ionic liquid droplet.

The fore-mentioned experimental studies document the application of IL solvents to separation problems encountered by chemicals and engineers. Our knowledge of the solubilizing properties of ionic liquids has now matured to the point where researchers can make educated guesses concerning which IL solvent is most likely to give the desired separation. This chapter will discuss predictions based upon the Abraham general solvation model (Abraham, 1993a,b; Abraham et al., 2004).

\section{Thermodynamic properties and chemical separations}

The thermodynamic basis for chemical separations using IL solvents is governed by solute partitioning between two immiscible or partly miscible phases. In the case of gas-liuqid chromatography the measured adjusted retention time, $t_{r}{ }^{\prime}$, is related to the solute's infinite dilution activity coefficient, $\gamma_{\text {solute }}{ }^{\infty}$, (Mutelet et al., 2010)

$$
\begin{gathered}
\ln \gamma_{1,2}^{\infty}=\ln \left(\frac{n_{\text {solvent }} \cdot R \cdot T}{V_{N} \cdot P_{1}^{0}}\right)-P_{1}^{0} \cdot \frac{B_{11}-V_{1}^{0}}{R T}+\frac{2 \cdot B_{13}-V_{1}^{\infty}}{R T} . J \cdot P_{0} \\
V_{N}=\frac{3}{2} x \frac{\left[\left(\frac{P_{\text {inlet }}}{P_{\text {outlet }}}\right)^{2}-1\right]}{\left[\left(\frac{P_{\text {inlet }}}{P_{\text {outlet }}}\right)^{3}-1\right]} U_{o} t_{r}{ }^{\prime} x \frac{T_{\text {col }}}{T_{\text {room }}}\left(1-\frac{P_{\text {water }}}{P_{\text {outlet }}}\right)
\end{gathered}
$$


and gas-to-liquid partition coefficient, $\mathrm{K}$,

$$
\log K=\log \left(\frac{R T}{\gamma_{\text {solute }}{ }^{\infty} P_{\text {solute }}{ }^{o} V_{\text {solvent }}}\right)
$$

through standard thermodynamic relationships. In Eqns. $2-4, \mathrm{~T}_{\text {col }}$ is the column temperature, $U_{o}$ is the flow rate of the carrier gas (mobile phase) measured at ambient room temperature $\left(\mathrm{T}_{\text {room }}\right)$ with a soap-bubble flowmeter, and $\mathrm{P}_{\text {water }}$ is the vapor pressure of water at $T_{\text {room. }} P_{\text {inlet }}$ and $P_{\text {outlet }}$ denote inlet and outlet pressures, respectively. Rigorous calculations do account for vapor phase nonideality, $B_{11}$ is the second virial coefficient of the solute (component 1) in the gaseous state at temperature $\mathrm{T}, \mathrm{B}_{13}$ is the mutual coefficient between the solute and mobile phase carrier gas, and $\mathrm{P}_{1}{ }^{\circ}$ is the solute's vapor pressure at temperature $\mathrm{T}, \mathrm{R}$ denotes the universal gas constant, $\mathrm{V}_{\text {solvent }}$ refers to the molar volume of the solvent at temperature $\mathrm{T}$, and $\mathrm{n}_{\text {solvent }}$ is the number of moles of solvent inside the column.

Chemical separation is achieved whenever two eluting solutes have sufficiently different retention times. Assuming an isothermal chromatographic separation, and that the column conditions remain constant during the course of the chemical separation, one can algebraically manipulate equations 2-4 to obtain the following expression

$$
\frac{t_{r, \text { solute } B^{\prime}}}{t_{r, \text { solute } A}{ }^{\prime}}=\left(\frac{\gamma_{A}{ }^{\infty}}{\gamma_{B}^{\infty}}\right) x\left(\frac{P_{A}{ }^{o}}{P_{B}{ }^{o}}\right)
$$

relating the ratio of adjusted retention times and the infinite dilution activity coefficients. The ratio of vapor pressures represents the separation (separation factor is $\alpha=\gamma_{A}{ }^{\infty} P_{A}{ }^{o} / \gamma_{B}^{\infty}$ $\mathrm{P}_{\mathrm{B}} \mathrm{o}$ ) that would be expected from the vapor pressure differences for the two solutes. The infinite dilution activity coefficient measures the enhanced separation that one could get from solute interactions with the liquid phase solvent. Solution models that accurately predict infinite dilution activity coefficients facilitate the design of manufacturing processes and analytical methods employing azeotropic distillations, gas stripping and gas chromatographic separations.

Chemical separations can also be achieved through solute partitioning between two condensed phases. Practical examples include liquid-liquid extraction and hplc. These partitioning processes are described by a partition coefficient as well

$$
P=\frac{C_{\text {solute, } \text { phase } \alpha}}{C_{\text {solute, phase } \beta}}
$$

For notation purposes gas-to-liquid partition coefficients are denoted as $\mathrm{K}$ in the chapter, while condensed phase-to-condensed phase partition coefficients are referred to as $P$. The notational distinction is needed because the Abraham solvation parameter model uses different linear free energy relationships (LFER) to predict $\log \mathrm{K}$ and $\log \mathrm{P}$ values.

From thermodynamic considerations it can be shown that the solute's partition coefficient is

$$
P=\frac{\gamma_{\text {solute, phase } \alpha}{ }^{\infty} V_{\text {phase } \alpha}}{\gamma_{\text {solute, phase } \beta}{ }^{\infty} V_{\text {phase } \beta}}
$$


a ratio of the product of the solute's infinite dilution activity coefficient in each phase ( $\gamma$ solute, phase $\alpha^{\infty}$ or $\gamma$ solute, phase $\beta^{\infty}$ ) times the molar volumes of each respective phase corrected for solvent $\alpha$ - solvent $\beta$ mutual saturation. The solute activity coefficients in Eqn. 7 pertain to the equilibrated phases in physical contact with one another, and thus are not necessarily the values that would be obtained for the solute dissolved in each pure solvent.

Practical partition coefficients should not be confused with indirect, hypothetical partitioning processes. The latter are also thermodynamic transfer processes. The Gibbs energy of transfer is

$$
\Delta \mathrm{G}_{\text {trans }}=-\mathrm{RT} \ln \text { Partition coefficient }
$$

It is possible to calculate $\Delta \mathrm{G}_{\text {trans }}$ values for solute transfer even when the two condensed phases are not in direct physical contact with each other. A hypothetical transfer process can be set up

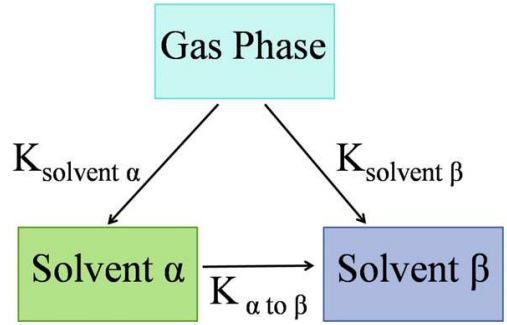

where the "hypothetical" solvent a-to-solvent $\beta$ partition coefficient can be calculated from

$$
\log \mathrm{P}_{\alpha-\beta}=\log \mathrm{Ks}_{\text {olvent } \beta}-\log \mathrm{K}_{\text {solvent } \alpha}
$$

the gas-to-solvent $\alpha$ and gas-to-solvent $\beta$ partition coefficients. Abraham model correlations have been developed for predicting "hypothetical" water-to-anhydrous IL solvents. Even though hypothetical these predicted $\log P$ values for water-to-anhydrous ILs are useful. The predicted values can be converted back to $\gamma_{\text {solute }}{ }^{\infty}$ values for solutes dissolved in the anhydrous IL using Eqns. 4 and 10.

$$
\log \mathrm{P}=\log \mathrm{K}_{\mathrm{IL}}-\log \mathrm{K}_{\mathrm{W}}
$$

In Eqn. $10 \mathrm{~K}_{\mathrm{W}}$ is the solute's gas-to-water partition coefficient.

Most of the Abraham model correlations that have been developed for predicting partition coefficients of solutes into IL solvents pertain to $298 \mathrm{~K}$ (Acree and Abraham, 2006; Abraham and Acree, 2006; Proctor et al., 2008; Sprunger et al., 2007b; Sprunger et al., 2008; Sprunger et al., 2009a,b,c; Sprunger et al., 2010; Abraham et al., 2009). Not all chemical separations take place at $298 \mathrm{~K}$ or even under isothermal conditions. There is a need to convert estimated partition coefficients for $298 \mathrm{~K}$ to other temperatures. From a thermodynamic standpoint, the gas-to-condensed phase partition coefficient, $\mathrm{K}$, and water-to-organic solvent partition coefficient, $\mathrm{P}$, can be estimated at other temperatures from measured partition coefficient at $298.15 \mathrm{~K}$ and the solute's enthalpy of solvation, $\Delta \mathrm{H}_{\text {solv }}$, or the enthalpy of transfer, $\Delta \mathrm{H}_{\text {trans, }}$ between the two condensed phases from Eqn. 11 or Eqn. 12.

$$
\log K(\text { at } T)-\log K(\text { at } 298.15 K)=\frac{-\Delta H_{\text {Solv }}}{2.303 R}(1 / T-1 / 298.15)
$$


and

$$
\log P(\text { at } T)-\log P(\text { at } 298.15 K)=\frac{-\Delta H_{\text {trans }}}{2.303 R}(1 / T-1 / 298.15)
$$

The enthalpy of transfer needed in Eqn. 12 is defined as

$$
\Delta \mathrm{H}_{\text {trans }}=\Delta \mathrm{H}_{\text {Solv }, \text { Org }}-\Delta \mathrm{H}_{\text {Solv, }, \mathrm{W}}
$$

the difference in the enthalpy of solvation of the solute in the specified organic solvent minus its enthalpy of solvation in water. The above equations assume zero heat capacity changes. Abraham model correlations have been developed for estimating $\Delta \mathrm{H}_{\text {solv }}$ for organic vapors and gases in IL solvents using ion-specific equation coefficients.

\section{The Abraham model: IL-specific correlations}

The Abraham general solvation model is one of the more useful approaches for the analysis and prediction of Gibbs energies of solute transfer in chemical and biochemical systems. Published applications include the partitioning of solutes into organic and IL solvents both from the gas phase and from water (Acree and Abraham, 2006; Abraham and Acree, 2006; Proctor et al., 2008; Sprunger et al., 2007b; Sprunger et al., 2008; Sprunger et al., 2009a,b,c; Sprunger et al., 2010; Abraham et al., 2009), partitioning of volatile organic compounds and drug molecules between human/rat blood and select body organs/tissues (Abraham et al., 2006; Abraham et al., 2007; Abraham et al., 2008), partitioning of solutes into humic acid (Mintz et al., 2008a), sorption of gases and organic solutes onto polydimethylsiloxane solidphase microextraction surfaces, (Sprunger et al., 2007c) and the distribution of solutes between water and sodium dodecyl sulfate (SDS) micelles (Sprunger et al., 2007a).

The method relies on two linear free energy relationships (lfers), one for transfer processes occurring within condensed phases (Abraham, 1993a,b; Abraham et al., 2004):

$$
\mathrm{SP}=\mathrm{c}+\mathrm{e} \cdot \mathbf{E}+\mathrm{s} \cdot \mathbf{S}+\mathrm{a} \cdot \mathbf{A}+\mathrm{b} \cdot \mathbf{B}+\mathrm{v} \cdot \mathbf{V}
$$

and one for processes involving gas-to-condensed phase transfer

$$
\mathrm{SP}=\mathrm{c}+\mathrm{e} \cdot \mathbf{E}+\mathrm{s} \cdot \mathbf{S}+\mathrm{a} \cdot \mathbf{A}+\mathrm{b} \cdot \mathbf{B}+\mathbf{l} \cdot \mathbf{L}
$$

The dependent variable, SP, is some property of a series of solutes in a fixed phase, which in the present study will be the logarithm of solute partition coefficient between two immiscible (or partly miscible) phases or the enthalpy of solvation. The independent variables, or descriptors, are solute properties as follows: $\mathbf{E}$ and $\mathbf{S}$ refer to the excess molar refraction and dipolarity/-polarizability descriptors of the solute, respectively, $\mathbf{A}$ and $\mathbf{B}$ are measures of the solute hydrogen-bond acidity and basicity, $\mathbf{V}$ is the McGowan volume of the solute and $\mathbf{L}$ is the logarithm of the solute gas phase dimensionless Ostwald partition coefficient into hexadecane at $298 \mathrm{~K}$. The first four descriptors can be regarded as measures of the tendency of the given solute to undergo various solute-solvent interactions. The latter two descriptors, $\mathbf{V}$ and $\mathbf{L}$, are both measures of solute size, and so will be measures of the solvent cavity term that will accommodate the dissolved solute. General dispersion interactions are also related to solute size, hence, both $\mathbf{V}$ and $\mathbf{L}$ will also describe the general solute-solvent interactions. Solute descriptors are available for more than 4,000 organic, organometallic and inorganic solutes. No single article lists all of the numerical values; 
however, a large compilation is available in one published review article (Abraham et al., 1993a), and in the supporting material that has accompanied several of our published papers (Abraham et al., 2006; Abraham et al., 2009; Mintz et al., 2007). Solute descriptors can be obtained by regression analysis using various types of experimental data, including water-to-solvent partitions, gas-to-solvent partitions, solubility data and chromatographic retention data as discussed elsewhere (Abraham et al., 2010; Zissimos et al., 2002a,b). There are also commercial software packages (Pharma Algorithms, 2006) and several published estimation schemes (Mutelet and Rogalski, 2001; Arey et al., 2005; Platts et al., 1999; Abraham and McGowan, 1987) for calculating the numerical values of solute descriptors from molecular structural information if one is unable to find the necessary partition, chromatographic and/or solubility data. For any fully characterized system/process (those with calculated values for the equation coefficients) further values of SP can be estimated for solutes with known values for the solute descriptors.

The usefulness of Eqns. 14 and 15 in the characterization of solvent phases is that he coefficients $e, s, a, b, l$ and $v$ are not just curve-fitting constants. The coefficients reflect particular solute-solvent interactions that correspond to chemical properties of the solvent phase. The excess molar refraction, $\mathbf{E}$, is defined from the solute refractive index, and hence the $e$ coefficient gives a measure of general solute-solvent dispersion interactions. The $\mathbf{V}$ and $\mathbf{L}$ descriptors were set up as measures of the endoergic effect of disrupting solvent-solvent bonds. However, solute volume is always well correlated with polarizability and so the $v$ and $l$ coefficients will include not only an endoergic cavity effect but also exoergic solutesolvent effects that arise through solute polarizability. The $\mathbf{S}$ descriptor is a measure of dipolarity and polarizability and hence the $s$ coefficient will reflect the ability of a solvent to undergo dipole- and dipole-induced dipole interactions with the solute. The A descriptor is a measure of solute hydrogen bond acidity, and hence the $a$ coefficient will reflect the complementary solvent hydrogen bond basicity. Similarly the $b$ coefficient will be a measure of solvent hydrogen bond acidity. All this is straightforward for gas-to-solvent partitions because there are no interactions to consider in the gas phase. For partition between solvents, the coefficients in Eqn. 14 then refer to differences between the properties of the two phases.

Listed in Tables 1 and 2 are the Abraham model equation coefficients that have been reported (Grubbs et al., 2010; Revelli et al., 2009; Mutelet et al., 2010; Revelli et al., 2010) or calculated for the chapter for describing solute transfer from the gas phase (log K) and from water $(\log \mathrm{P})$ into 1-methyl-3-ethylimidazolium bis(trifluoromethyl-sulfonyl)imide, $\left([\mathrm{MEIm}]^{+}\left[(\mathrm{Tf})_{2} \mathrm{~N}\right]^{-}\right), \quad$ 1-methyl-3-butylimidazolium bis(trifluoromethylsulfonyl)-imide, $\left([\mathrm{MBIm}]^{+}\left[(\mathrm{Tf})_{2} \mathrm{~N}\right]^{-}\right), \quad$ 1-methyl-3-hexyl-imidazolium bis(trifluoromethylsulfonyl)imide, $\left([\mathrm{MHIm}]^{+}\left[(\mathrm{Tf})_{2} \mathrm{~N}\right]^{-}\right), \quad$ trimethylbutylammonium bis(trifluoromethyl-sulfonyl)imide, $\left(\left[\mathrm{M}_{3} \mathrm{BAm}\right]^{+}\left[(\mathrm{Tf})_{2} \mathrm{~N}\right]-\right)$, hexyltrimethylammonium bis(trifluoromethylsulfonyl)imide, $\left(\left[\mathrm{HexM}_{3} \mathrm{Am}\right]^{+}\left[(\mathrm{Tf})_{2} \mathrm{~N}\right]^{-}\right), \quad$ 1,3-dimethoxyimidazolium bis((trifluoromethyl)sulfonyl)imide $\left(\left[(\mathrm{Meo})_{2} \mathrm{Im}\right]^{+}\left[(\mathrm{Tf})_{2} \mathrm{~N}\right]^{-}\right)$, 1-ethanol-3-methylimidazolium bis(trifluoromethyl)sulfonylimide, $\left([\mathrm{EtOHMIm}]+\left[(\mathrm{Tf})_{2} \mathrm{~N}\right]-\right)$, trihexyltetradecylphosphonium bis(trifluoromethyl-sulfonyl)imide, $\left(\left[\mathrm{H}_{3} \mathrm{TdP}\right]^{+}\left[(\mathrm{Tf})_{2} \mathrm{~N}\right]-\right)$, 1-methylethylether-3-methyl-imidazolium bis((trifluoromethyl)sulfonyl)imide, ([MeoeMIm $\left.]^{+}\left[(\mathrm{Tf})_{2} \mathrm{~N}\right]-\right)$, 1-methyl-3-butylimidazolium tetrafluoroborate, $\left([\mathrm{MBIm}]^{+}\left[\mathrm{BF}_{4}\right]^{-}\right)$, 1-methyl-3-octylimidazolium tetrafluoroborate, $\left([\mathrm{MOIm}]^{+}\left[\mathrm{BF}_{4}\right]^{-}\right)$, 1-methyl-3-butyl-imidazolium hexafluorophosphate, $\left([\mathrm{MBIm}]^{+}\left[\mathrm{PF}_{6}\right]^{-}\right)$, 1methyl-3-ethylimidazolium ethylsulfate, $\left([\mathrm{MEIm}]^{+}\left[\mathrm{EtSO}_{4}\right]^{-}\right)$, 1-methyl-3-butylimidazolium octylsulfate, $\left([\mathrm{MBIm}]^{+}\left[\mathrm{OtSO}_{4}\right]^{-}\right)$, 1-methyl-3-butylimidazolium trifluoromethanesulfonate, 


\begin{tabular}{|c|c|c|c|c|c|c|c|c|c|}
\hline Solvent & c & $\mathrm{e}$ & $\mathrm{s}$ & a & $\mathrm{b}$ & 1 & $\mathrm{Na}$ & SD & $\mathrm{R}^{2}$ \\
\hline \multirow[t]{2}{*}{$\left([\mathrm{MBIm}]^{+}\left[\mathrm{BF}_{4}\right]^{-}\right)$} & -0.600 & 0.356 & 2.534 & 3.312 & 0.284 & 0.604 & 66 & 0.099 & 0.997 \\
\hline & $(0.026)$ & (0.075) & $(0.068)$ & $(0.100)$ & $(0.074)$ & $(0.011)$ & & & \\
\hline \multirow[t]{2}{*}{$\left([\mathrm{EtOHMIm}]+\left[(\mathrm{Tf})_{2} \mathrm{~N}\right]^{-}\right)$} & -0.793 & 0.139 & 2.404 & 2.587 & 1.353 & 0.581 & 81 & 0.100 & 0.993 \\
\hline & $(0.047)$ & $(0.061)$ & $(0.065)$ & $(0.074)$ & $(0.077)$ & $(0.011)$ & & & \\
\hline \multirow[t]{2}{*}{$\left([\mathrm{MBIm}]^{+}\left[\mathrm{PF}_{6}\right]^{-}\right)$} & -0.460 & -0.191 & 2.747 & 2.228 & 0.363 & 0.663 & 91 & 0.154 & 0.994 \\
\hline & $(0.033)$ & $(0.081)$ & $(0.086)$ & $(0.097)$ & $(0.101)$ & $(0.015)$ & & & \\
\hline \multirow[t]{2}{*}{$\left([\mathrm{MBIm}]+\left[(\mathrm{Tf})_{2} \mathrm{~N}\right]^{-}\right)$} & -0.394 & 0.089 & 1.969 & 2.283 & 0.873 & 0.696 & 104 & 0.111 & 0.994 \\
\hline & $(0.029)$ & $(0.068)$ & $(0.085)$ & $(0.104)$ & $(0.113)$ & $(0.009)$ & & & \\
\hline \multirow[t]{2}{*}{$\left([\mathrm{MHIm}]^{+}\left[(\mathrm{Tf})_{2} \mathrm{~N}\right]^{-}\right)$} & -0.348 & -0.240 & 2.060 & 2.184 & 0.561 & 0.754 & 77 & 0.117 & 0.993 \\
\hline & $(0.032)$ & $(0.102)$ & $(0.102)$ & $(0.136)$ & $(0.113)$ & $(0.010)$ & & & \\
\hline \multirow[t]{2}{*}{$\left([\mathrm{MOIm}]^{+}\left[\mathrm{BF}_{4}\right]^{-}\right)$} & -0.409 & -0.049 & 1.562 & 2.911 & 0.803 & 0.778 & 61 & 0.140 & 0.987 \\
\hline & $(0.050)$ & $(0.115)$ & $(0.135)$ & $(0.125)$ & $(0.155)$ & $(0.013)$ & & & \\
\hline \multirow[t]{2}{*}{$\left([\mathrm{MEIm}]+\left[(\mathrm{Tf})_{2} \mathrm{~N}\right]^{-}\right)$} & -0.486 & 0.068 & 2.296 & 2.278 & 0.988 & 0.651 & 65 & 0.094 & 0.996 \\
\hline & $(0.041)$ & $(0.058)$ & $(0.052)$ & $(0.052)$ & $(0.126)$ & $(0.067)$ & & & \\
\hline \multirow[t]{2}{*}{$\left(\left[\mathrm{M}_{3} \mathrm{BAm}\right]^{+}\left[(\mathrm{Tf})_{2} \mathrm{~N}\right]^{-}\right)$} & -0.457 & 0.000 & 2.188 & 2.375 & 0.663 & 0.668 & 58 & 0.120 & 0.990 \\
\hline & $(0.048)$ & & $(0.150)$ & $(0.198)$ & $(0.197)$ & $(0.013)$ & & & \\
\hline \multirow[t]{2}{*}{ ([MBIm]+[Trif]-) } & -0.666 & 0.179 & 2.264 & 3.856 & 0.567 & 0.698 & 51 & 0.105 & 0.989 \\
\hline & $(0.057)$ & $(0.124)$ & $(0.130)$ & $(0.140)$ & $(0.118)$ & $(0.018)$ & & & \\
\hline \multirow[t]{2}{*}{$\left([\mathrm{MeomMIm}]^{+}\left[(\mathrm{Tf})_{2} \mathrm{~N}\right]^{-}\right)$} & -0.508 & 0.000 & 2.635 & 2.379 & 0.418 & 0.602 & 52 & 0.108 & 0.981 \\
\hline & $(0.076)$ & & $(0.087)$ & $(0.129)$ & $(0.093)$ & $(0.018)$ & & & \\
\hline \multirow[t]{2}{*}{$\left.\left([\mathrm{Meo})_{2} \mathrm{Im}\right]^{+}\left[(\mathrm{Tf})_{2} \mathrm{~N}\right]^{-}\right)$} & -0.762 & -0.013 & 2.557 & 2.427 & 1.157 & 0.584 & 48 & 0.084 & 0.989 \\
\hline & $(0.063)$ & $(0.046)$ & $(0.072)$ & $(0.106)$ & $(0.077)$ & $(0.015)$ & & & \\
\hline \multirow[t]{2}{*}{$\left([\mathrm{CNPrMIm}]^{+}\left[\mathrm{C}(\mathrm{CN})_{2}\right]^{-}\right)$} & -1.489 & -0.418 & 3.089 & 4.807 & 0.626 & 0.644 & 45 & 0.121 & 0.987 \\
\hline & (0.098) & $(0.117)$ & $(0.115)$ & $(0.163)$ & $(0.135)$ & $(0.025)$ & & & \\
\hline \multirow[t]{2}{*}{$\left([\mathrm{MEIm}]^{+}\left[\mathrm{C}(\mathrm{CN})_{2}\right]^{-}\right)$} & -0.888 & 0.361 & 2.833 & 4.690 & 0.364 & 0.596 & 74 & 0.109 & 0.989 \\
\hline & $(0.055)$ & $(0.082)$ & $(0.075)$ & $(0.104)$ & $(0.074)$ & $(0.014)$ & & & \\
\hline \multirow[t]{2}{*}{$\left(\left[\mathrm{HexM}_{3} \operatorname{Im}\right]^{+}\left[(\mathrm{Tf})_{2}\right]^{-}\right)$} & -0.462 & 0.000 & 2.073 & 2.022 & 0.637 & 0.684 & 50 & 0.123 & 0.968 \\
\hline & $(0.090)$ & & $(0.081)$ & $(0.150)$ & $(0.103)$ & $(0.021)$ & & & \\
\hline \multirow[t]{2}{*}{$\left(\left[\mathrm{H}_{3} \mathrm{TdP}\right]^{+}\left[(\mathrm{Tf})_{2}\right]^{-}\right)$} & -0.406 & -0.576 & 1.602 & 2.358 & -0.009 & 0.959 & 59 & 0.112 & 0.982 \\
\hline & $(0.058)$ & $(0.123)$ & $(0.125)$ & $(0.156)$ & $(0.147)$ & $(0.018)$ & & & \\
\hline \multirow[t]{2}{*}{$\left([\mathrm{MBIm}]^{+}\left[\mathrm{OtSO}_{4}\right]^{-}\right)$} & -0.228 & -0.287 & 1.940 & 4.862 & -0.302 & 0.880 & 56 & 0.116 & 0.984 \\
\hline & $(0.081)$ & $(0.093)$ & $(0.103)$ & $(0.168)$ & $(0.140)$ & $(0.023)$ & & & \\
\hline \multirow[t]{2}{*}{$\left([\mathrm{MEIm}]^{+}\left[\mathrm{EtSO}_{4}\right]^{-}\right)$} & -0.677 & 0.000 & 2.557 & 5.327 & 0.000 & 0.588 & 53 & 0.125 & 0.986 \\
\hline & $(0.062)$ & & $(0.072)$ & $(0.072)$ & & (0.015) & & & \\
\hline
\end{tabular}

a Statistical information: $\mathrm{N}$ is the number of data points, $\mathrm{SD}$ is the standard deviation, and $\mathrm{R}^{2}$ is the squared correlation coefficient.

Table 1. Abraham model correlation equation coefficients for the transfer of solutes from gas to the anhydrous (dry) ionic liquid solvents (log K correlation). 


\begin{tabular}{|c|c|c|c|c|c|c|c|c|c|}
\hline Solvent & c & e & $\mathrm{s}$ & a & $\mathrm{b}$ & $\mathrm{v}$ & $\mathrm{Na}$ & SD & $\mathrm{R}^{2}$ \\
\hline \multirow[t]{2}{*}{$\left([\mathrm{MBIm}]^{+}\left[\mathrm{BF}_{4}\right]^{-}\right)$} & -0.082 & 0.454 & 0.541 & -0.427 & -4.583 & 2.961 & 66 & 0.132 & 0.992 \\
\hline & $(0.049)$ & $(0.092)$ & $(0.095)$ & $(0.134)$ & $(0.099)$ & $(0.057)$ & & & \\
\hline \multirow[t]{2}{*}{$\left([\mathrm{EtOHMIm}]^{+}\left[(\mathrm{Tf})_{2} \mathrm{~N}\right]^{-}\right)$} & -0.402 & 0.304 & 0.470 & -1.082 & -3.510 & 2.977 & 79 & 0.133 & 0.990 \\
\hline & $(0.078)$ & $(0.078)$ & $(0.091)$ & $(0.099)$ & $(0.103)$ & $(0.063)$ & & & \\
\hline \multirow[t]{2}{*}{$\left([\mathrm{MBIm}]^{+}\left[\mathrm{PF}_{6}\right]^{-}\right)$} & -0.056 & 0.193 & 0.737 & -1.351 & -4.526 & 3.109 & 86 & 0.154 & 0.988 \\
\hline & $(0.046)$ & $(0.080)$ & $(0.087)$ & $(0.100)$ & $(0.102)$ & $(0.059)$ & & & \\
\hline \multirow[t]{2}{*}{$\left([\mathrm{MBIm}]^{+}\left[(\mathrm{Tf})_{2} \mathrm{~N}\right]^{-}\right)$} & -0.018 & 0.416 & 0.153 & -1.312 & -4.187 & 3.347 & 101 & 0.131 & 0.994 \\
\hline & $(0.044)$ & $(0.084)$ & $(0.105)$ & $(0.131)$ & $(0.139)$ & $(0.039)$ & & & \\
\hline \multirow[t]{2}{*}{$\left([\mathrm{MHIm}]^{+}\left[(\mathrm{Tf})_{2} \mathrm{~N}\right]^{-}\right)$} & -0.065 & 0.010 & 0.260 & -1.476 & -4.313 & 3.587 & 75 & 0.115 & 0.996 \\
\hline & $(0.042)$ & $(0.105)$ & $(0.103)$ & $(0.135)$ & $(0.111)$ & $(0.039)$ & & & \\
\hline \multirow[t]{2}{*}{$\left([\mathrm{MOIm}]^{+}\left[\mathrm{BF}_{4}\right]^{-}\right)$} & -0.115 & 0.210 & 0.000 & -0.511 & -4.338 & 3.617 & 59 & 0.159 & 0.994 \\
\hline & $(0.076)$ & $(0.130)$ & & $(0.143)$ & $(0.177)$ & $(0.063)$ & & & \\
\hline \multirow[t]{2}{*}{$\left([\mathrm{MEIm}]+\left[(\mathrm{Tf})_{2} \mathrm{~N}\right]^{-}\right)$} & 0.029 & 0.351 & 0.202 & -1.684 & -3.585 & 3.059 & 64 & 0.119 & 0.993 \\
\hline & $(0.048)$ & $(0.103)$ & $(0.121)$ & $(0.163)$ & $(0.137)$ & $(0.055)$ & & & \\
\hline \multirow[t]{2}{*}{$\left(\left[\mathrm{M}_{3} \mathrm{BAm}\right]^{+}\left[(\mathrm{Tf})_{2} \mathrm{~N}\right]^{-}\right)$} & 0.047 & -0.051 & 0.356 & -1.262 & -4.400 & 3.209 & 57 & 0.120 & 0.996 \\
\hline & $(0.060)$ & $(0.133)$ & $(0.154)$ & $(0.202)$ & $(0.198)$ & $(0.049)$ & & & \\
\hline \multirow[t]{2}{*}{$([\mathrm{MBIm}]+[$ Trif $])$} & -0.217 & 0.195 & 0.497 & 0.062 & -4.310 & 3.282 & 51 & 0.130 & 0.992 \\
\hline & $(0.091)$ & $(0.143)$ & $(0.166)$ & $(0.176)$ & $(0.145)$ & $(0.084)$ & & & \\
\hline \multirow[t]{2}{*}{$\left([\mathrm{MeomMIm}]^{+}\left[(\mathrm{Tf})_{2} \mathrm{~N}\right]^{-}\right)$} & -0.140 & -0.067 & 0.818 & -1.185 & -4.523 & 3.105 & 48 & 0.120 & 0.993 \\
\hline & $(0.120)$ & $(0.097)$ & $(0.122)$ & $(0.172)$ & $(0.116)$ & $(0.117)$ & & & \\
\hline \multirow[t]{2}{*}{$\left(\left[(\mathrm{Meo})_{2} \mathrm{Im}\right]^{+}\left[(\mathrm{Tf})_{2} \mathrm{~N}\right]^{-}\right)$} & -0.412 & -0.104 & 0.761 & -1.124 & -3.776 & 3.055 & 46 & 0.130 & 0.993 \\
\hline & $(0.133)$ & $(0.123)$ & $(0.124)$ & $(0.171)$ & $(0.118)$ & $(0.106)$ & & & \\
\hline \multirow[t]{2}{*}{$\left([\mathrm{CNPrMIm}]^{+}\left[\mathrm{C}(\mathrm{CN})_{2}\right]^{-}\right)$} & -0.928 & 0.373 & 1.224 & 1.042 & -4.307 & 3.046 & 44 & 0.150 & 0.988 \\
\hline & $(0.156)$ & $(0.146)$ & $(0.154)$ & $(0.207)$ & $(0.166)$ & $(0.125)$ & & & \\
\hline \multirow[t]{2}{*}{$\left([\mathrm{MEIm}]^{+}\left[\mathrm{C}(\mathrm{CN})_{2}\right]^{-}\right)$} & -0.404 & 0.344 & 0.945 & 0.987 & -4.526 & 2.957 & 70 & 0.126 & 0.992 \\
\hline & $(0.105)$ & $(0.095)$ & $(0.100)$ & $(0.133)$ & $(0.088)$ & $(0.087)$ & & & \\
\hline \multirow[t]{2}{*}{$\left(\left[\mathrm{HexM}_{3} \operatorname{Im}\right]^{+}\left[(\mathrm{Tf})_{2}\right]^{-}\right)$} & -0.275 & 0.000 & 0.407 & -1.478 & 4.320 & 3.510 & 48 & 0.140 & 0.994 \\
\hline & $(0.136)$ & & $(0.115)$ & $(0.176)$ & $(0.114)$ & $(0.111)$ & & & \\
\hline \multirow[t]{2}{*}{$\left(\left[\mathrm{H}_{3} \mathrm{TdP}\right]^{+}\left[(\mathrm{Tf})_{2}\right]^{-}\right)$} & -0.155 & -0.163 & -0.029 & -1.271 & -5.042 & 4.246 & 59 & 0.136 & 0.996 \\
\hline & $(0.092)$ & $(0.146)$ & $(0.157)$ & $(0.192)$ & $(0.179)$ & $(0.085)$ & & & \\
\hline \multirow[t]{2}{*}{$\left([\mathrm{MBIm}]^{+}\left[\mathrm{OtSO}_{4}\right]^{-}\right)$} & -0.050 & 0.198 & 0.179 & 1.146 & -5.154 & 4.008 & 55 & 0.179 & 0.986 \\
\hline & $(0.155)$ & $(0.132)$ & $(0.175)$ & $(0.296)$ & $(0.228)$ & $(0.135)$ & & & \\
\hline \multirow[t]{2}{*}{$\left([\mathrm{MEIm}]+\left[\mathrm{EtSO}_{4}\right]^{-}\right)$} & -0.079 & -0.021 & 0.554 & 1.491 & -4.944 & 2.895 & 53 & 0.147 & 0.992 \\
\hline & $(0.090)$ & $(0.158)$ & $(0.183)$ & $(0.228)$ & $(0.211)$ & $(0.068)$ & & & \\
\hline
\end{tabular}

a Statistical information: $\mathrm{N}$ is the number of data points, $\mathrm{SD}$ is the standard deviation, and $\mathrm{R}^{2}$ is the squared correlation coefficient.

Table 2. Abraham model correlation equation coefficients for the transfer of solutes from water to the anhydrous (dry) ionic liquid solvents (log P correlation). 
$\left([\mathrm{MBIm}]^{+}[\text {Trif }]^{-}\right)$, 1-methyl-3-ethyl-imidazolium dicyanamide, $\left([\mathrm{MEIm}]^{+}\left[\mathrm{C}(\mathrm{CN})_{2}\right]^{-}\right)$, and 1-(3cyanopropyl)-3-methylimidazolium dicyanamide, ([CNPrMIm $\left.]^{+}\left[\mathrm{C}(\mathrm{CN})_{2}\right]^{-}\right)$. The IL-specific equation coefficients were obtained by regressing infinite dilution activity coefficients and Henry's law constants into the respective IL in accordance with Eqns. 14 and 15. Solubility data for gaseous solutes are often reported in the literature as Henry's law constants, which are related to $\log \mathrm{K}$ by

$$
\log K=\log \left(\frac{R T}{K_{\text {Henry }} V_{\text {solvent }}}\right)
$$

The statistics of each derived correlation are quite good as reflected by the low standard deviations (SD) and near unity values for the squared correlation coefficients $\left(\mathrm{R}^{2}\right)$. The standard error in each equation coefficient is denoted in parenthesis immediately below the coefficient. The remaining statistical information is as follows: $\mathrm{N}$ denotes the number of experimental data points for the given IL data set.

The log P correlations do pertain to solute transfer from water-to-anhydrous IL solvent. As noted above these represent a hypothetical partitioning processes, and calculated values based on the equation coefficients listed in Table 2 may be different than the experimental $\log \mathrm{P}$ values determined by direct partitioning of the solute between water and the IL solvent. At the present time there has been few practical water-to-IL systems studied. Abraham et al. (2003) reported log $\mathrm{P}$ correlations for 1-butyl-3-methylimidazoium hexafluorophosphate, $\left([\mathrm{BMIm}]^{+}\left[\mathrm{PF}_{6}\right]^{-}\right)$

$$
\log \mathrm{P}=-0.17+0.45 \mathrm{E}+0.23 \mathrm{~S}-1.76 \mathrm{~A}-1.83 \mathbf{B}+2.15 \mathrm{~V}
$$

and for 1-hexyl-3-methylimidazolium hexafluorophosphate, $\left([\mathrm{HMIm}]^{+}\left[\mathrm{PF}_{6}\right]^{-}\right)$

$$
\log \mathrm{P}=-0.13+0.05 \mathrm{E}+0.40 \mathrm{~S}-1.48 \mathrm{~A}-2.11 \mathrm{~B}+2.30 \mathrm{~V}
$$

Room temperature ionic liquids have been used as a solvent media for organic synthesis. Most (if not all) of the classic synthetic methods have been performed in IL solvents. Much higher product yields and shorter reaction times have been reported for ILs than for the more conventional organic solvents. Product removal from the IL reaction media can often be accomplished by carbon dioxide supercritical fluid extraction. Many imidazolium-based ionic liquids are nearly insoluble in supercritical carbon dioxide, even at very high pressures. Roth (2009) recently reviewed the partitioning of organic compounds between IL solvents and supercritical fluids, with particular emphasis on supercritical carbon dioxide.

There have been very few attempts to correlate/predict the partition coefficients of organic solutes in IL solvents - supercritical fluid carbon dioxide systems. Planeta and coworkers (Planeta and Roth 2005; Planeta et al., 2007; Planeta et al., 2009) correlated the relative partition coefficients of solutes in the $\left([\mathrm{BMIm}]^{+}\left[\mathrm{BF}_{4}\right]^{-}\right) / \mathrm{CO}_{2}$, $\left([\mathrm{BMIm}]^{+}[\mathrm{MeSO} 4]^{-}\right) / \mathrm{CO}_{2}$ and ([ThtdP $\left.]^{+}[\mathrm{Cl}]^{-}\right) / \mathrm{CO}_{2}$ with the Abraham model

$$
\log \frac{P_{\text {solute, } A}}{P_{\text {naphthalene }}}=e E_{A}+s S_{A}+a A_{A}+b B_{A}+v V_{A}
$$

The authors used naphthalene as the reference solute, and the descriptors in Eqn. 19 pertain to solute A. The derived correlations did provide a satisfactory description of the 
experimental partition coefficient data, suggesting that the Abraham model could be used in the preliminary design stage of real-world extraction processes employing $\mathrm{IL} / \mathrm{CO}_{2}$ systems. The solubilizing properties of supercritical carbon dioxide are temperature and pressuredependent. Correlations derived for one set of experimental conditions might not apply at other operating temperatures and processes.

\section{Abraham model: Ion-specific equation coefficients}

The physical and chemical properties of ILs can be modified by changing the cation-anion combination. There are currently synthetic procedures for making more than 300 different ILs and the number is likely to grow in number in future years as more applications are discovered. It would be impractical to develop an Abraham model correlation for each known IL. To address this concern, Sprunger and coworkers (Sprunger et al., 2007b; Sprunger et al., 2008; Spurnger et al., 2009c; Grubbs et al., 2010) modified the basic Abraham solvation parameter model for the gas-to-IL partition coefficient

$$
\begin{gathered}
\log K=c_{\text {cation }}+c_{\text {anion }}+\left(\mathrm{e}_{\text {cation }}+\mathrm{e}_{\text {anion }}\right) \mathbf{E}+\left(\mathrm{s}_{\text {cation }}+\mathrm{s}_{\text {anion }}\right) \mathbf{S}+\left(\mathrm{a}_{\text {cation }}+\mathrm{a}_{\text {anion }}\right) \mathbf{A}+ \\
\left(\mathrm{b}_{\text {cation }}+\mathrm{b}_{\text {anion }}\right) \mathbf{B}+\left(\mathrm{l}_{\text {cation }}+\mathrm{l}_{\text {anion }}\right) \mathbf{L}
\end{gathered}
$$

and water-to-IL partition coefficient

$$
\begin{gathered}
\log \mathrm{P}=\mathrm{c}_{\text {cation }}+\mathrm{c}_{\text {anion }}+\left(\mathrm{e}_{\text {cation }}+\mathrm{e}_{\text {anion }}\right) \mathbf{E}+\left(\mathrm{s}_{\text {cation }}+\mathrm{s}_{\text {anion }}\right) \mathbf{S}+\left(\mathrm{a}_{\text {cation }}+\mathrm{a}_{\text {anion }}\right) \mathbf{A} \\
+\left(\mathrm{b}_{\text {cation }}+\mathrm{b}_{\text {anion }}\right) \mathbf{B}+\left(\mathrm{v}_{\text {cation }}+\mathrm{v}_{\text {anion }}\right) \mathbf{V}
\end{gathered}
$$

by rewriting each of the six solvent equation coefficients as the summation of their respective cation and anion contribution. In separating the equation coefficients it was assumed that the soltue's interaction with a given cation is not influenced by the surrounding IL anion, and that the solute's interaction with a given anion is unaffected by the surrounding IL cation. Once calculated, the ion-specific equation coefficients can be combined to build the Abraham model correlation for the desired cation-anion pair.

During the three years since the modified version was first suggested we have periodically updated the numerical values of the coefficients as new experimental data became available. For this chapter we have reanalyzed our large $\log \mathrm{K}$ and $\log \mathrm{P}$ databases for solutes dissolved in ILs to yield the following correlations

$$
\begin{gathered}
\log K=\sum_{\text {cation }}\left(c_{\text {cation }}+e_{\text {cation }} E+s_{\text {cation }} S+a_{\text {cation }} A+b_{\text {cation }} B+l_{\text {cation }} L\right)+ \\
\sum_{\text {anion }}\left(c_{\text {anion }}+e_{\text {anion }} E+s_{\text {anion }} S+a_{\text {anion }} A+b_{\text {anion }} B+l_{\text {anion }} L\right) \\
\left(\mathrm{N}=2084, \mathrm{R}^{2}=0.998, \mathrm{R}^{2}\right. \text { adj } \\
=0.998, \mathrm{SD}=0.112, \mathrm{~F}=5810)
\end{gathered}
$$

and

$$
\begin{gathered}
\log P=\sum_{\text {cation }}\left(c_{\text {cation }}+e_{\text {cation }} E+s_{\text {cation }} S+a_{\text {cation }} A+b_{\text {cation }} B+v_{\text {cation }} V\right)+ \\
\sum_{\text {anion }}\left(c_{\text {anion }}+e_{\text {anion }} E+s_{\text {anion }} S+a_{\text {anion }} A+b_{\text {anion }} B+v_{\text {anion }} V\right) \\
\left(\mathrm{N}=2054, \mathrm{R}^{2}=0.997, \mathrm{R}^{2}\right. \text { adj } \\
=0.996, \mathrm{SD}=0.139, \mathrm{~F}=2720)
\end{gathered}
$$


The calculated cation-specific and anion-specific equation coefficients are listed in Tables 3 and 4, along with their respective standard errors. For the most part, the larger standard errors are noted in the equation coefficients for those ions for which experimental data is limited. The number of data points for the individual ions range from a minimum of $22 \mathrm{log}$ $\mathrm{K}$ values for the $\left[\mathrm{B}(\mathrm{CN})_{4}\right]^{-}$anion to more than $400 \log \mathrm{K}$ values for the $[\mathrm{BMIm}]^{+}$and [EMIm] $]^{+}$ cations and $\left[(\mathrm{Tf})_{2} \mathrm{~N}\right]-$ anion, which is more than sufficient for the regression analysis. The 23 cation-specific equation coefficients and 13 anion-specific equation coefficients that have been reported in Tables 3 and 4 can be combined to give predictive $\log \mathrm{K}$ and $\log \mathrm{P}$ correlations for a total of 299 (23 times 13) IL solvents. Predicted $\log \mathrm{K}$ and $\log \mathrm{P}$ values can be converted to infinite dilution activity coefficients, $\gamma_{\text {solute }}{ }^{\infty}$, through Eqns.4 and 10. Sprunger et al. found that very little (if any) loss in descriptive/predictive ability resulted from splitting the equation coefficients into the individual ion contributions.

One note regarding the computation methodology that we used in calculating of the ionspecific equation coefficients. The cation-specific and anion-specific coefficients are paired in that each cation-specific coefficient goes together with its anion-specific counterpart to make up a summed value that the five solute descriptors are multiplied by. If one were to perform a regression analysis on Eqns. 20 - 23 the statistical software would generate numerical equation coefficients based on some reference point. The reference point would likely depend on the particular database used and the software's built-in convergence routine. Calculation of additional ion values at some later time would be difficult as there would be no guarantee that the next regression analyses would find the same reference point. In accordance with the computation methodology suggested by Sprunger et al. (2007b) the anion-specific equation coefficients of [(Tf $\left.)_{2} \mathrm{~N}\right]$ - were set equal to zero. Setting fixed reference points is not uncommon in thermodynamics. For example in calculating the chemical potentials of individual ions, the chemical potential of the hydrogen ion in water is defined to be zero and the values of all other ions are computed relative to this defined thermodynamic reference state.

\begin{tabular}{|c|c|c|c|c|c|c|}
\hline Ion & $\mathrm{C}_{\text {ion }}$ & $\mathrm{e}_{\text {ion }}$ & $S_{\text {ion }}$ & $a_{\text {ion }}$ & $b_{\text {ion }}$ & $l_{\text {ion }}$ \\
\hline \multicolumn{7}{|l|}{ CATIONSa } \\
\hline [MEIm] $^{+}$ & -0.502 & 0.050 & 2.421 & 2.266 & 0.875 & 0.650 \\
\hline$(\mathrm{N}=420)^{\mathrm{b}}$ & $(0.026)$ & $(0.073)$ & $(0.088)$ & $(0.112)$ & $\begin{array}{l}(0.100) \\
\end{array}$ & (0.009) \\
\hline$[\mathrm{BMIm}]^{+}$ & -0.407 & 0.064 & 2.071 & 2.279 & 0.761 & 0.699 \\
\hline$(\mathrm{N}=402)$ & $(0.023)$ & $(0.053)$ & $(0.062)$ & $(0.077)$ & $(0.078)$ & $(0.007)$ \\
\hline$[\mathrm{MHIm}]^{+}$ & -0.339 & -0.135 & 2.034 & 2.365 & 0.505 & 0.757 \\
\hline$(\mathrm{N}=238)$ & $(0.027)$ & $(0.078)$ & $(0.093)$ & $(0.108)$ & $(0.100)$ & $(0.008)$ \\
\hline 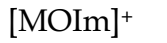 & -0.229 & -0.246 & 1.292 & 1.808 & 1.146 & 0.836 \\
\hline$(\mathrm{N}=114)$ & $(0.032)$ & $(0.090)$ & $(0.114)$ & $(0.108)$ & $(0.127)$ & $(0.010)$ \\
\hline$\left[\mathrm{M}_{3} \mathrm{BAm}\right]^{+}$ & -0.457 & -0.005 & 2.188 & 2.375 & 0.663 & 0.668 \\
\hline$(\mathrm{N}=58)$ & $(0.045)$ & $(0.123)$ & $(0.141)$ & $(0.187)$ & $(0.185)$ & $(0.012)$ \\
\hline$\left[\mathrm{M}_{2} \mathrm{EIm}\right]^{+}$ & -0.611 & 0.188 & 2.380 & 2.101 & 0.899 & 0.667 \\
\hline$(\mathrm{N}=39)$ & $(0.072)$ & $(0.134)$ & $(0.142)$ & $(0.175)$ & $(0.138)$ & $(0.022)$ \\
\hline [4-BMPy] $^{+}$ & -0.479 & 0.141 & 2.293 & 2.364 & 0.672 & 0.713 \\
\hline
\end{tabular}




\begin{tabular}{|c|c|c|c|c|c|c|}
\hline$(\mathrm{N}=76)$ & $(0.055)$ & $(0.115)$ & $(0.132)$ & $(0.138)$ & $(0.121)$ & $(0.017)$ \\
\hline [3-BMPy] $^{+}$ & -0.263 & 0.000 & 2.368 & 2.265 & 0.271 & 0.688 \\
\hline$(\mathrm{N}=36)$ & $(0.115)$ & & $(0.260)$ & $(0.253)$ & $(0.246)$ & $(0.034)$ \\
\hline$[\mathrm{NEP}]^{+}$ & -0.668 & 0.246 & 2.399 & 2.403 & 0.936 & 0.672 \\
\hline$(\mathrm{N}=31)$ & $(0.076)$ & $(0.192)$ & $(0.180)$ & $(0.209)$ & $(0.150)$ & $(0.028)$ \\
\hline$\left[\mathrm{PM}_{2} \operatorname{Im}\right]^{+}$ & -0.822 & 0.780 & 2.357 & 3.432 & 0.926 & 0.526 \\
\hline$(\mathrm{N}=34)$ & $(0.120)$ & $(0.169)$ & $(0.196)$ & $(0.227)$ & $(0.207)$ & $(0.035)$ \\
\hline$\left[\mathrm{HexM}_{3} \mathrm{Am}\right]^{+}$ & -0.459 & -0.039 & 2.096 & 2.021 & 0.624 & 0.684 \\
\hline$(\mathrm{N}=50)$ & $(0.083)$ & $(0.102)$ & $(0.095)$ & $(0.138)$ & $(0.100)$ & $(0.020)$ \\
\hline [HexdMIm] $^{+}$ & 0.019 & -0.452 & 0.821 & 1.810 & 0.523 & 0.997 \\
\hline$(\mathrm{N}=31)$ & $(0.142)$ & $(0.157)$ & $(0.165)$ & $(0.245)$ & $(0.187)$ & $(0.044)$ \\
\hline [HxomMIm] $^{+}$ & -0.463 & -0.394 & 2.478 & 2.428 & 0.337 & 0.786 \\
\hline$(\mathrm{N}=34)$ & (0.109) & $(0.212)$ & $(0.272)$ & $(0.205)$ & $(0.217)$ & $(0.033)$ \\
\hline$\left[(\mathrm{Hxom})_{2} \mathrm{Im}\right]^{+}$ & -0.314 & -0.479 & 2.076 & 2.376 & 0.287 & 0.835 \\
\hline$(\mathrm{N}=34)$ & $(0.109)$ & $(0.212)$ & $(0.272)$ & $(0.205)$ & $(0.217)$ & $(0.033)$ \\
\hline$\left[(\mathrm{Meo})_{2} \mathrm{Im}\right]^{+}$ & -0.762 & -0.013 & 2.557 & 2.427 & 1.154 & 0.584 \\
\hline$(\mathrm{N}=48)$ & $(0.083)$ & $(0.104)$ & $(0.096)$ & $(0.140)$ & $(0.101)$ & $(0.020)$ \\
\hline 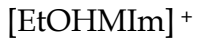 & -0.843 & 0.098 & 2.438 & 2.684 & 1.402 & 0.578 \\
\hline$(\mathrm{N}=151)$ & $(0.039)$ & $(0.059)$ & $(0.062)$ & $(0.073)$ & $(0.074)$ & $(0.010)$ \\
\hline$\left[\mathrm{H}_{3} \mathrm{TdP}\right]^{+}$ & -0.406 & -0.576 & 1.602 & 2.338 & -0.009 & 0.959 \\
\hline$(\mathrm{N}=59)$ & $(0.058)$ & $(0.124)$ & $(0.126)$ & $(0.157)$ & $(0.149)$ & $(0.018)$ \\
\hline [MeoeMIm] $^{+}$ & -0.507 & -0.015 & 2.644 & 2.378 & 0.413 & 0.602 \\
\hline$(\mathrm{N}=52)$ & $(0.078)$ & $(0.020)$ & $(0.094)$ & $(0.135)$ & $(0.100)$ & $(0.019)$ \\
\hline [BMPyrr] $^{+}$ & -0.570 & -0.075 & 2.687 & 2.338 & 0.570 & 0.711 \\
\hline$(\mathrm{N}=31)$ & $(0.076)$ & $(0.300)$ & $(0.391)$ & $(0.273)$ & $(0.282)$ & $(0.025)$ \\
\hline [CNPrMIm] $^{+}$ & -1.103 & 0.108 & 2.677 & 2.383 & 1.136 & 0.699 \\
\hline$(\mathrm{N}=45)$ & $(0.110)$ & $(0.155)$ & $(0.159)$ & $(0.216)$ & $(0.177)$ & $(0.029)$ \\
\hline [PrOHPy] $^{+}$ & -0.895 & -0.065 & 3.006 & 3.013 & 1.483 & 0.673 \\
\hline$(\mathrm{N}=38)$ & $(0.117)$ & $(0.202)$ & $(0.250)$ & $(0.240)$ & $(0.247)$ & $(0.034)$ \\
\hline$\left[\mathrm{E}_{3} \mathrm{~S}\right]^{+}$ & -0.606 & -0.196 & 2.992 & 2.444 & 0.355 & 0.690 \\
\hline$(\mathrm{N}=31)$ & $(0.112)$ & $(0.278)$ & $(0.368)$ & $(0.241)$ & $(0.254)$ & $(0.033)$ \\
\hline$\left[\mathrm{MO}_{3} \mathrm{Am}\right]^{+}$ & -0.387 & -0.130 & 1.460 & 2.327 & 0.501 & 0.927 \\
\hline$(\mathrm{N}=32)$ & $(0.064)$ & $(0.222)$ & $(0.353)$ & $(0.336)$ & $(0.463)$ & $(0.020)$ \\
\hline \multicolumn{7}{|l|}{ ANIONSc } \\
\hline$\left[(\mathrm{Tf})_{2} \mathrm{~N}\right]^{-}$ & 0.000 & 0.000 & 0.000 & 0.000 & 0.000 & 0.000 \\
\hline \multicolumn{7}{|l|}{$(\mathrm{N}=860)$} \\
\hline$\left[\mathrm{BF}_{4}\right]^{-}$ & -0.203 & 0.217 & 0.370 & 1.093 & -0.408 & -0.068 \\
\hline$(\mathrm{N}=307)$ & $(0.027)$ & $(0.066)$ & $(0.073)$ & $(0.091)$ & $(0.086)$ & $(0.009)$ \\
\hline$\left[\mathrm{PF}_{6}\right]^{-}$ & -0.033 & -0.184 & 0.647 & 0.007 & -0.362 & -0.085 \\
\hline
\end{tabular}




\begin{tabular}{|c|c|c|c|c|c|c|}
\hline$(\mathrm{N}=169)$ & $(0.029)$ & $(0.068)$ & $(0.075)$ & $(0.090)$ & $(0.092)$ & $(0.010)$ \\
\hline$\left[\mathrm{EtSO}_{4}\right]^{-}$ & -0.176 & -0.035 & 0.123 & 3.048 & -0.862 & -0.063 \\
\hline$(\mathrm{N}=53)$ & $(0.062)$ & $(0.143)$ & $(0.162)$ & $(0.205)$ & $(0.189)$ & $(0.016)$ \\
\hline$[\mathrm{Trif}]^{-}$ & -0.301 & 0.030 & 0.329 & 1.712 & -0.321 & 0.011 \\
\hline$(\mathrm{N}=163)$ & $(0.044)$ & $(0.114)$ & $(0.133)$ & $(0.147)$ & $(0.128)$ & $(0.015)$ \\
\hline$\left[\mathrm{F}_{3} \mathrm{Ac}\right]^{-}$ & -0.305 & -0.191 & 0.499 & 3.265 & -0.336 & 0.019 \\
\hline$(\mathrm{N}=32)$ & $(0.055)$ & $(0.233)$ & $(0.343)$ & $(0.686)$ & $(0.725)$ & $(0.019)$ \\
\hline$[\mathrm{OtSO}]^{-}$ & 0.277 & -0.232 & -0.150 & 2.402 & -1.015 & 0.120 \\
\hline$(\mathrm{N}=58)$ & $(0.072)$ & $(0.099)$ & $(0.117)$ & $(0.175)$ & $(0.156)$ & $(0.018)$ \\
\hline$[\mathrm{SCN}]^{-}$ & -0.727 & 0.284 & 0.783 & 2.607 & -0.288 & -0.006 \\
\hline$(\mathrm{N}=91)$ & $(0.069)$ & $(0.153)$ & $(0.202)$ & $(0.153)$ & $(0.167)$ & $(0.020)$ \\
\hline$\left[\mathrm{C}(\mathrm{CN})_{2}\right]^{-}$ & -0.387 & 0.310 & 0.412 & 2.424 & -0.510 & -0.055 \\
\hline$(\mathrm{N}=119)$ & $(0.063)$ & $(0.113)$ & $(0.118)$ & $(0.156)$ & $(0.126)$ & $(0.017)$ \\
\hline$\left[\mathrm{E}_{2} \mathrm{PO}\right]_{4}^{-}$ & 0.089 & 0.145 & -0.184 & 5.186 & -0.966 & 0.064 \\
\hline$(\mathrm{N}=38)$ & $(0.105)$ & $(0.175)$ & $(0.182)$ & $(0.237)$ & $(0.184)$ & $(0.035)$ \\
\hline$\left[\mathrm{FAP}^{-}\right.$ & 0.179 & -0.015 & 0.063 & -1.314 & 0.238 & -0.053 \\
\hline$(\mathrm{N}=144)$ & $(0.050)$ & $(0.099)$ & $(0.117)$ & $(0.129)$ & $(0.136)$ & $(0.015)$ \\
\hline$\left[\mathrm{B}(\mathrm{CN})_{4}\right]^{-}$ & 0.243 & -0.347 & 0.445 & 0.034 & -0.225 & -0.005 \\
\hline$(\mathrm{N}=23)$ & $(0.157)$ & $(0.469)$ & $(0.607)$ & $(0.839)$ & $(0.775)$ & $(0.047)$ \\
\hline$\left[\mathrm{NO}_{3}\right]^{-}$ & -0.211 & 0.624 & 0.577 & 2.578 & -0.788 & -0.191 \\
\hline$(\mathrm{N}=27)$ & $(0.224)$ & $(0.200)$ & $(0.203)$ & $(0.328)$ & $(0.192)$ & $(0.067)$ \\
\hline
\end{tabular}

a Cation abbreviations: [4-BMPy] ${ }^{+}$is 4-methyl-N-butylpyridinium cation; [3-BMPy] ${ }^{+}$is 3-methyl-Nbutylpyridinium cation; [MEIm] ${ }^{+}$is 1-methyl-3-ethylimidazolium cation ; $\left[\mathrm{M}_{2} \text { EIm }\right]^{+}$is 1 ,2-dimethyl-3ethylimidazolium cation; [MBIm] ${ }^{+}$is 1-methyl-3-butylimidazolium cation; [MHIm] ${ }^{+}$is1-methyl-3hexylimidazolium cation; $\left[\mathrm{M}_{3} \mathrm{BAm}\right]^{+}$is trimethylbutylammonium cation; $[\mathrm{MOIm}]^{+}$is 1-methyl-3octylimidazolium cation; [NEPy] ${ }^{+}$is N-ethylpyridinium cation; [ $\left.\mathrm{PM}_{2} \mathrm{Im}\right]^{+}$is 1-propyl-2,3dimethylimidazolium cation; $\left[(\mathrm{Meo})_{2} \mathrm{Im}\right]+$ is 1,3 -dimethoxy-imidazolium cation; [EtOHMIm] ${ }^{+}$is 1ethanol-3-methylimidazolium cation; $\left[\mathrm{H}_{3} \mathrm{TdP}\right]^{+}$is trihexyltetradecylphosphonium cation; $[\mathrm{MeoeMIm}]^{+}$ is 1-methylethylether-3-methyl-imidazolium cation; [HxomMIm] ${ }^{+}$is 1-hexyloxymethyl-3methylimidazolium; [(Hxom $\left.)_{2} \mathrm{Im}\right]^{+}$is 1,3-dihexyloxymethylimidazolium cation; [PrOHPy $]^{+}$is $1-(3-$ hydroxypropyl)pyridinium; [BMPyrr] ${ }^{+}$is 1-butyl-1-methylpyrrolidinum cation; [CMPrMIm] $]^{+}$is $1-(3-$ cyanopropyl)-3-methylimidazolium cation; [HexM3 $\mathrm{Am}]^{+}$is hexyltrimethylammonium cation; [HexdMIm] $^{+}$is 1-hexadecyl-3-methylimidazolium cation; [ $\left.\mathrm{E}_{3} \mathrm{~S}\right]^{+}$is triethylsulfonium cation; and $\left[\mathrm{MO}_{3} \mathrm{Am}\right]^{+}$is methyl(trioctyl)ammonium cation.

b Number of experimental data points associated with the specified ion.

c Anion abbreviations: [(Tf $\left.)_{2} \mathrm{~N}\right]^{-}$is bis(trifluoromethylsulfonyl)imide anion; $\left[\mathrm{BF}_{4}\right]^{-}$is tetrafluoroborate anion; $\left[\mathrm{PF}_{6}\right]^{-}$is hexafluorophosphate anion; $\left[\mathrm{EtSO}_{4}\right]^{-}$is ethylsulfate anion; [Trif]- is the trifluoromethanesulfonate anion; $\left[\mathrm{F}_{3} \mathrm{Ac}\right]^{-}$is the trifluoroacetate anion; $\left[\mathrm{OtSO}_{4}\right]^{-}$is octylsulfate anion; $[\mathrm{SCN}]^{-}$is thiocyanate anion; $\left[\mathrm{C}(\mathrm{CN})_{2}\right]^{-}$is dicyanamide anion; $\left[\mathrm{E}_{2} \mathrm{PO}_{4}\right]^{-}$is diethylphosphate anion; $\left[\mathrm{B}(\mathrm{CN})_{4}\right]^{-}$is tetracyanoborate anion; $\left[\mathrm{NO}_{3}\right]^{-}$is nitrate anion; and $[\mathrm{FAP}]^{-}$is tris(pentafluoroethyl)trifluorophosphate anion.

Table 3. Cation-Specific and Anion-Specific Equation Coefficients for the Abraham Model Gas-to-RTIL Correlation (Eqn.22) 


\begin{tabular}{|c|c|c|c|c|c|c|}
\hline Ion ${ }^{a}$ & $C_{\text {ion }}$ & $\mathrm{e}_{\text {ion }}$ & $S_{\text {ion }}$ & $a_{\text {ion }}$ & $b_{\text {ion }}$ & $\mathrm{V}_{\text {ion }}$ \\
\hline \multicolumn{7}{|l|}{ CATIONS } \\
\hline [MEIm] $^{+}$ & -0.037 & 0.152 & 0.554 & -1.422 & -4.011 & 3.150 \\
\hline$(\mathrm{N}=415)^{\mathrm{b}}$ & $(-0.043)$ & $(0.091)$ & $(0.113)$ & $(0.142)$ & $(0.125)$ & $(0.045)$ \\
\hline [BMIm] $^{+}$ & -0.028 & 0.448 & 0.180 & -1.399 & -4.160 & 3.332 \\
\hline$(\mathrm{N}=392)$ & $(0.036)$ & $(0.065)$ & $(0.079)$ & $(0.099)$ & (0.098) & $(0.034)$ \\
\hline [MHIm] $^{+}$ & -0.040 & 0.252 & 0.165 & -1.263 & -4.375 & 3.586 \\
\hline$(\mathrm{N}=236)$ & $(0.045)$ & $(0.098)$ & $(0.116)$ & $(0.136)$ & $(0.124)$ & $(0.041)$ \\
\hline [MOIm] $^{+}$ & -0.011 & 0.009 & -0.150 & -1.641 & -3.98 & 3.872 \\
\hline$(\mathrm{N}=112)$ & $(0.055)$ & $(0.111)$ & $(0.143)$ & $(0.137)$ & $(0.159)$ & $(0.052)$ \\
\hline$\left[\mathrm{M}_{3} \mathrm{BAm}\right]^{+}$ & 0.047 & -0.051 & 0.356 & -1.262 & -4.400 & 3.209 \\
\hline$(\mathrm{N}=57)$ & $(0.071)$ & $(0.156)$ & $(0.180)$ & $(0.236)$ & $(0.231)$ & $(0.058)$ \\
\hline$\left[\mathrm{M}_{2} \mathrm{EIm}\right]^{+}$ & -0.095 & 0.292 & 0.443 & -1.681 & -4.024 & 3.174 \\
\hline$(\mathrm{N}=39)$ & $(0.115)$ & $(0.156)$ & $(0.187)$ & $(0.224)$ & $(0.172)$ & $(0.103)$ \\
\hline [4-BMPy] $^{+}$ & -0.128 & 0.207 & 0.591 & -1.349 & -4.283 & 3.433 \\
\hline$(\mathrm{N}=76)$ & $(0.087)$ & $(0.133)$ & $(0.169)$ & $(0.176)$ & $(0.151)$ & $(0.079)$ \\
\hline [3-BMPy] $^{+}$ & 0.134 & 0.170 & 0.678 & -1.204 & -4.934 & 3.324 \\
\hline$(\mathrm{N}=36)$ & $(0.151)$ & $(0.309)$ & $(0.317)$ & $(0.325)$ & $(0.258)$ & $(0.173)$ \\
\hline$[\mathrm{NEP}]^{+}$ & -0.322 & 0.323 & 0.552 & -1.234 & -3.951 & 3.370 \\
\hline$(\mathrm{N}=31)$ & $(0.130)$ & $(0.222)$ & $(0.231)$ & $(0.273)$ & $(0.189)$ & $(0.140)$ \\
\hline$\left[\mathrm{PM}_{2} \mathrm{Im}\right]^{+}$ & -0.499 & 0.685 & 0.568 & -0.238 & -4.006 & 2.907 \\
\hline$(\mathrm{N}=34)$ & $(0.174)$ & $(0.192)$ & $(0.256)$ & $(0.284)$ & $(0.258)$ & $(0.151)$ \\
\hline$\left[\mathrm{HexM}_{3} \mathrm{Am}\right]^{+}$ & -0.278 & 0.013 & 0.401 & -1.476 & -4.315 & 3.512 \\
\hline$(\mathrm{N}=48)$ & $(0.139)$ & $(0.127)$ & $(0.129)$ & $(0.176)$ & $(0.123)$ & $(0.111)$ \\
\hline$\left[_{\text {HexdMIm] }}^{+}\right.$ & 0.167 & -0.218 & -0.448 & -1.884 & -4.597 & 4.461 \\
\hline$(\mathrm{N}=31)$ & $(0.212)$ & $(0.182)$ & $(0.227)$ & $(0.311)$ & $(0.234)$ & $(0.190)$ \\
\hline [HxomMIm] $^{+}$ & -0.039 & -0.645 & 1.184 & -1.374 & -4.779 & 3.609 \\
\hline$(\mathrm{N}=34)$ & $(0.163)$ & $(0.255)$ & $(0.335)$ & $(0.256)$ & $(0.275)$ & $(0.142)$ \\
\hline$\left[(\mathrm{Hxom})_{2} \mathrm{Im}\right]^{+}$ & 0.107 & -0.628 & 0.747 & -1.441 & -4.808 & 3.750 \\
\hline$(\mathrm{N}=34)$ & $(0.163)$ & $(0.255)$ & $(0.335)$ & $(0.256)$ & $(0.275)$ & $(0.142)$ \\
\hline$\left[(\mathrm{Meo})_{2} \mathrm{Im}\right]^{+}$ & -0.412 & -0.104 & 0.761 & -1.124 & -3.776 & 3.055 \\
\hline$(\mathrm{N}=34)$ & $(0.142)$ & $(0.131)$ & $(0.132)$ & $(0.183)$ & $(0.126)$ & $(0.113)$ \\
\hline 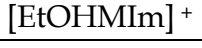 & -0.404 & 0.229 & 0.517 & -1.026 & -3.493 & 2.931 \\
\hline$(\mathrm{N}=148)$ & $(0.061)$ & $(0.070)$ & $(0.080)$ & $(0.092)$ & $(0.091)$ & $(0.052)$ \\
\hline$\left[\mathrm{H}_{3} \mathrm{TdP}\right]^{+}$ & -0.155 & -0.164 & -0.055 & -1.317 & -4.985 & 4.250 \\
\hline$(\mathrm{N}=59)$ & $(0.093)$ & $(0.148)$ & $(0.154)$ & $(0.189)$ & $(0.168)$ & $(0.086)$ \\
\hline [MeoeMIm] $^{+}$ & -0.161 & 0.014 & 0.658 & -1.282 & -4.262 & 3.125 \\
\hline$(\mathrm{N}=50)$ & $(0.131)$ & $(0.026)$ & $(0.127)$ & $(0.173)$ & $(0.124)$ & $(0.104)$ \\
\hline 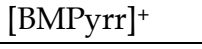 & -0.182 & -0.760 & 2.188 & -1.449 & -5.039 & 3.423 \\
\hline
\end{tabular}




\begin{tabular}{|c|c|c|c|c|c|c|}
\hline$(\mathrm{N}=31)$ & $(0.127)$ & $(0.368)$ & $(0.487)$ & $(0.344)$ & $(0.355)$ & $(0.120)$ \\
\hline [CNPrMIm] $^{+}$ & -0.596 & 0.172 & 0.724 & -1.497 & -3.509 & 3.284 \\
\hline$(\mathrm{N}=44)$ & $(0.179)$ & $(0.194)$ & $(0.210)$ & $(0.277)$ & $(0.220)$ & $\begin{array}{l}(0.148) \\
\end{array}$ \\
\hline [PrOHPy $^{+}$ & -0.302 & -0.299 & 1.476 & -0.503 & -3.760 & 3.125 \\
\hline$(\mathrm{N}=38)$ & $(0.175)$ & $(0.249)$ & $(0.311)$ & $(0.299)$ & $(0.310)$ & $(0.151)$ \\
\hline$\left[\mathrm{E}_{3} \mathrm{~S}\right]^{+}$ & -0.062 & -1.347 & 2.716 & -1.550 & -5.274 & 3.242 \\
\hline$(\mathrm{N}=31)$ & $(0.170)$ & $(0.348)$ & $(0.458)$ & $(0.302)$ & $(0.325)$ & $(0.148)$ \\
\hline$\left[\mathrm{MO}_{3} \mathrm{Am}\right]^{+}$ & -0.092 & 0.000 & -0.146 & -1.129 & -4.609 & 4.114 \\
\hline$(\mathrm{N}=32)$ & $(0.103)$ & & $(0.135)$ & $(0.116)$ & $(0.274)$ & $(0.095)$ \\
\hline \multicolumn{7}{|l|}{ ANIONS } \\
\hline$\left[(\mathrm{Tf})_{2} \mathrm{~N}\right]^{-}$ & 0.000 & 0.000 & 0.000 & 0.000 & 0.000 & 0.000 \\
\hline \multicolumn{7}{|l|}{$(\mathrm{N}=843)$} \\
\hline$\left[\mathrm{BF}_{4}\right]^{-}$ & -0.084 & 0.129 & 0.240 & 1.108 & -0.401 & -0.296 \\
\hline$(\mathrm{N}=305)$ & $(0.045)$ & $(0.080)$ & $(0.094)$ & $(0.116)$ & $(0.108)$ & $(0.043)$ \\
\hline$\left[\mathrm{PF}_{6}\right]^{-}$ & 0.000 & -0.299 & 0.544 & 0.088 & -0.321 & -0.264 \\
\hline$(\mathrm{N}=164)$ & & $(0.083)$ & $(0.096)$ & $(0.115)$ & $(0.114)$ & $(0.048)$ \\
\hline$\left[\mathrm{EtSO}_{4}\right]^{-}$ & -0.042 & -0.173 & 0.000 & 2.913 & -0.933 & -0.256 \\
\hline$(\mathrm{N}=53)$ & $(0.095)$ & $(0.174)$ & & $(0.258)$ & $(0.236)$ & $(0.078)$ \\
\hline$[\text { Trif] }]^{-}$ & -0.193 & -0.339 & 0.506 & 1.520 & -0.293 & -0.047 \\
\hline$(\mathrm{N}=162)$ & $(0.072)$ & $(0.136)$ & $(0.166)$ & $(0.187)$ & $(0.161)$ & $(0.068)$ \\
\hline$\left[\mathrm{F}_{3} \mathrm{Ac}\right]^{-}$ & -0.288 & -0.771 & 0.891 & 2.255 & 0.332 & 0.049 \\
\hline$(\mathrm{N}=32)$ & $(0.094)$ & $(0.270)$ & $(0.426)$ & $(0.854)$ & $(0.904)$ & $(0.096)$ \\
\hline$\left[\mathrm{OtSO}_{4}\right]^{-}$ & 0.013 & -0.258 & 0.000 & 2.537 & -1.001 & 0.678 \\
\hline$(\mathrm{N}=56)$ & $(0.126)$ & $(0.121)$ & & $(0.249)$ & $(0.201)$ & $(0.109)$ \\
\hline$[\mathrm{SCN}]^{-}$ & -0.566 & -0.757 & 1.878 & 2.390 & -0.843 & -0.120 \\
\hline$(\mathrm{N}=91)$ & $(0.105)$ & $(0.191)$ & $(0.251)$ & $(0.193)$ & $(0.212)$ & $(0.190)$ \\
\hline$\left[\mathrm{C}(\mathrm{CN})_{2}\right]^{-}$ & -0.287 & 0.179 & 0.351 & 2.350 & -0.525 & -0.255 \\
\hline$(\mathrm{N}=116)$ & $(0.105)$ & $(0.139)$ & $(0.156)$ & $(0.200)$ & $(0.158)$ & $(0.094)$ \\
\hline$\left[\mathrm{E}_{2} \mathrm{PO}_{4}\right]^{-}$ & 0.059 & 0.136 & -0.120 & 5.217 & -1.029 & 0.196 \\
\hline$(\mathrm{N}=38)$ & $(0.164)$ & $(0.194)$ & $(0.242)$ & $(0.302)$ & $(0.231)$ & $(0.156)$ \\
\hline$[\mathrm{FAP}]^{-}$ & 0.132 & -0.171 & 0.121 & -1.314 & 0.244 & -0.107 \\
\hline$(\mathrm{N}=144)$ & $(0.079)$ & $(0.122)$ & $(0.148)$ & $(0.162)$ & $(0.170)$ & $(0.069)$ \\
\hline$\left[\mathrm{B}(\mathrm{CN})_{4}\right]^{-}$ & 0.346 & -1.011 & 1.195 & -0.105 & -0.676 & -0.070 \\
\hline$(\mathrm{N}=23)$ & $(0.237)$ & $(0.618)$ & $(0.766)$ & $(1.053)$ & $(0.952)$ & $(0.205)$ \\
\hline$\left[\mathrm{NO}_{3}\right]^{-}$ & -0.037 & 0.322 & 0.376 & 2.539 & -0.801 & -0.676 \\
\hline$(\mathrm{N}=27)$ & $(0.303)$ & $(0.215)$ & $(0.283)$ & $(0.403)$ & $(0.243)$ & $(0.268)$ \\
\hline
\end{tabular}

a Cation and anion abbreviations are given in Table 3.

b Number of experimental data points associated with the specified ion.

Table 4. Cation-Specific and Anion-Specific Equation Coefficients for the Abraham Model Water-to-RTIL Correlation (Eqn.23) 
Both LFERs are statistically very good, and describe experimental $\log \mathrm{K}$ and $\log \mathrm{P}$ databases that cover a $12.5 \log$ unit and $8.7 \log$ unit range to within standard deviations of $0.112 \log$ units (Eqn. 22) and $0.139 \log$ units (Eqn. 23) as shown in Figures 4 and 5. Based on the limited number of replicate independent activity coefficient measurements that have been

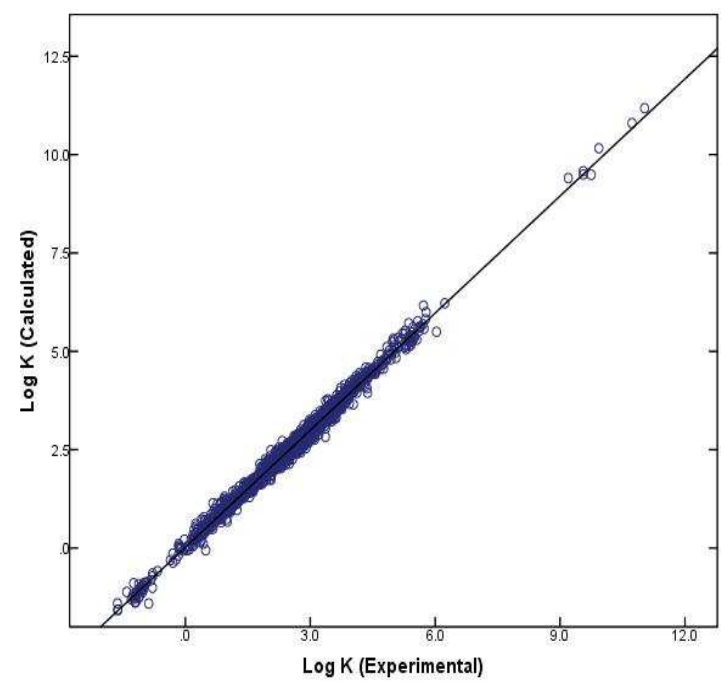

Fig. 4. Comparison between the 2084 experimental $\log \mathrm{K}$ data points and predicted values based on Eqn. 22.

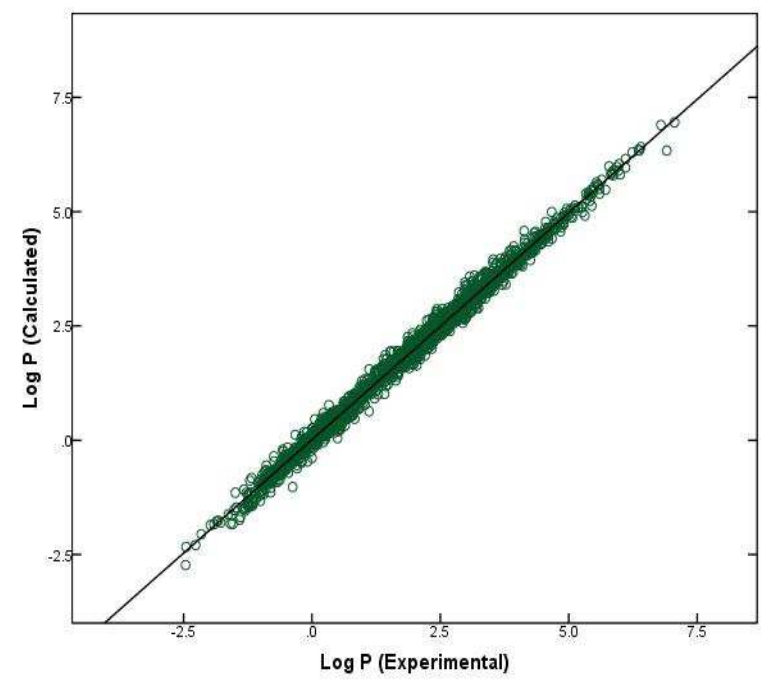

Fig. 5. Comparison between the 2054 experimental $\log \mathrm{P}$ data points and predicted values based on Eqn. 23. 
performed for solutes dissolved in ILs we believe that 0.05 to $0.15 \log$ units would be a reasonable guesstimate of the uncertainty associated with the experimental log $\mathrm{K}$ values. Slightly larger standard deviations are expected for the $\log \mathrm{P}$ correlation which also includes the experimental uncertainties in the $\log \mathrm{K}_{\mathrm{w}}$ data used to convert the $\log \mathrm{K}$ values to $\log \mathrm{P}$.

Careful examination of the individual residuals between the calculated and observed values revealed that Equation 22 described $70.1 \%$ (1461 of 2084 values) of the gas-to-IL partition coefficient data to within $0.1 \log$ units, $92.0 \%$ (1918 of 2084 values) to within $0.2 \log$ units, and $98.1 \%$ (2045 of 2084 values) to within $0.3 \log$ units of observed values. Only $1.9 \%$ of the predicted $\log \mathrm{K}$ values fell more than $0.3 \log$ units from the experimental value, with the largest residual being $-0.55 \log$ units. Similar results were noted for Eqn. $23 ; 56.8 \%$ of the back-calculated water-to-IL partition coefficients differed from the observed value by less than $0.1 \log$ units, $85.8 \%$ differed by less than $0.2 \log$ units, and $98.7 \%$ differed by less than $0.3 \log$ units. Less than $1.3 \%$ of the predicted $\log P$ values were more than $0.3 \log$ units from the observed value. The largest residual for the $\log P$ calculations is $-0.61 \log$ units. These values should reflect the predictive ability that Eqns. 22 and 23 would exhibit in terms of predicting partition coefficients for new compounds dissolved in ILs containing the 23 cations and 13 anions given in Tables 3 and 4, provided that the solute descriptors of the compounds fall within the area of predictive chemical space defined by the calculated equation coefficients: $\mathbf{E}=0.000$ to $\mathbf{E}=1.500 ; \mathbf{S}=0.000$ to $\mathbf{S}=1.720 ; \mathbf{A}=0.000$ to $\mathbf{A}=1.030 ; \mathbf{B}=$ 0.000 to $\mathbf{B}=1.280 ; \mathbf{V}=0.109$ to $\mathbf{V}=1.799$; and $\mathbf{L}=-1.200$ to $\mathbf{L}=7.833$. A few of the ionspecific data sets spanned a slightly smaller range of solute descriptors. Predicted activity coefficients can be converted to infinite dilution activity coefficients, $\gamma$ solute $^{\infty}$, through Eqns. 4 and 10 .

The major advantage of splitting the equation coefficients into individual cation-specific and anion-specific contributions is that one can make predictions for more RTILs. Normally one needs partition coefficient data for 40-50 solutes dissolved in a given RTIL to develop a RTIL-specific Abraham model correlation. By combining all of the experimental data for a RTIL containing lets say either a 1-methyl-3-octylimidazolium cation, [MOIm] ${ }^{+}$, and trifluoromethane-sulfonate anion, [Trif]-, it may be possible to calculate [MOIm] ${ }^{+}$-specific and [Trif]-specific equation coefficients where there was too few data points for the [MOIm $]^{+}[\text {Trif] }]^{-}$ionic liquid to develop a meaningful correlation. Revelli et al. (2010a) further extended the Abraham model's predictive capability for IL solvents by further splitting the cation-specific equation coefficient into functional group values

$$
\begin{gathered}
\log K=\sum_{\text {group }} c_{i} n_{i}+\sum_{\text {group }} e_{i} n_{i} E+\sum_{\text {group }} s_{i} n_{i} S+\sum_{\text {group }} a_{i} n_{i} A+\sum_{\text {group }} b_{i} n_{i} B+\sum_{\text {group }} l_{i} n_{i} L+ \\
\left(c_{\text {anion }}+e_{\text {anion }} E+s_{\text {anion }} S+a_{\text {anion }} A+b_{\text {anion }} B+l_{\text {anion }} L\right)
\end{gathered}
$$

and

$$
\begin{aligned}
& \log P=\sum_{\text {group }} c_{i} n_{i}+\sum_{\text {group }} e_{i} n_{i} E+\sum_{\text {group }} s_{i} n_{i} S+\sum_{\text {group }} a_{i} n_{i} A+\sum_{\text {group }} b_{i} n_{i} B+\sum_{\text {group }} v_{i} n_{i} V+ \\
& \left(c_{\text {anion }}+e_{\text {anion }} E+s_{\text {anion }} S+a_{\text {abion }} A+b_{\text {anion }} B+v_{\text {anion }} V\right)
\end{aligned}
$$

where $n_{i}$ is the number of times a particular functional group appears in the cation. The authors were able to mathematically describe the 1450 available gas-to-IL partition coefficients (log K values) and 1410 water-to-IL partition coefficients (log P values) with 21 


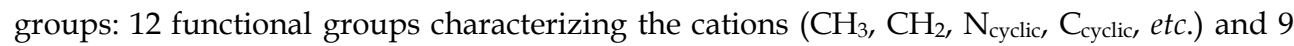
individual anions $\left(\left[\mathrm{PF}_{6}\right]^{-},\left[\mathrm{BF}_{4}\right]^{-},[\mathrm{SCN}]^{-}\right.$, etc. $)$to within 0.15 and $0.17 \mathrm{log}$ units, respectively. The number of functional group values is likely to increase in future years as more experimental data becomes available for functionalized IL solvents. In selecting a predictive method, we suggest that the first choice by the IL-specific Abraham equation if available, followed by the ion-specific Abraham model, and then the Abraham group contribution model of Revelli et al. For many IL solvents the group contribution model will be the only option available at the present time.

\section{Abraham model: Enthalpy of solvation correlations}

Abraham model correlations constructed from the ion-specific equation coefficients in Tables 3 and 4 pertain to $298.15 \mathrm{~K}$. A method is needed for extrapolating the predicted $\log \mathrm{K}$ and $\log \mathrm{P}$ values to other temperatures for applications involving azeotropic distillation and temperature-programmed gas-liquid chromatographic separation. The majority of experimental data used in the $\log \mathrm{K}$ and $\log \mathrm{P}$ regressions came from published gas-liquid chromatographic retention measurements. As part of the experimental studies the authors determined the infinite dilution coefficients of volatile solutes in IL solvents at several temperatures. For the majority of measurements the median temperature corresponded to $323 \pm 5 \mathrm{~K}$. Solutes studied include inert gases, diatomic gas molecules, linear and cyclic alkanes and alkenes (up to dodecane), alkylbenzenes, linear and branched alcohols, linear and cyclic monoethers (plus 1,4-dioxane), chlorinated methanes and a few of the smaller aldehydes and ketones. The solute descriptor space defined by these compounds would be: $\mathbf{E}=0.000$ to $\mathbf{E}=0.850 ; \mathbf{S}=0.000$ to $\mathbf{S}=0.900 ; \mathbf{A}=0.000$ to $\mathbf{A}=0.430 ; \mathbf{B}=0.000$ to $\mathbf{B}=0.650 ; \mathbf{V}$ $=0.109$ to $\mathbf{V}=1.800$; and $\mathbf{L}=-1.200$ to $\mathbf{L}=5.700$. The predictive area of chemical space spanned by this set of solutes is smaller than the range covered by the log K (Eqn. 22) and $\log \mathrm{P}$ (Eqn. 23) correlations.

The solute's molar enthalpy of solution in the IL is calculated from the variation of $\gamma_{\text {solute }}{ }^{\infty}$ with temperature, i.e., $\Delta \mathrm{Hex}^{\infty}=\mathrm{R} \partial \ln \gamma_{\text {solute }} / \partial(1 / \mathrm{T})$. Enthalpies of solution determined in this fashion assume that $\Delta \mathrm{Hex}^{\infty}$ is independent of temperature over the range of the experimental measurements. Enthalpies of solvation are calculated by

$$
\begin{gathered}
\Delta \mathrm{H}_{\mathrm{Solv}}=\Delta \mathrm{Hex}^{\infty}-\Delta \mathrm{H}_{\mathrm{Vap}} \\
\Delta \mathrm{H}_{\text {Solv }}=\Delta \mathrm{Hex}^{\infty}-\Delta \mathrm{H}_{\text {Sub }}
\end{gathered}
$$

the solute's enthalpy of vaporization $\left(\Delta \mathrm{H}_{V a p}\right.$, liquid solute) or enthalpy of sublimation $\left(\Delta \mathrm{H}_{\mathrm{Sub}}\right.$, solid solute) from the molar enthalpy of solution. Large compilations of $\Delta \mathrm{H}_{\mathrm{Vap}}$ and $\Delta \mathrm{H}_{\text {Sub }}$ data are available in the published literature (Chickos and Acree, 2002; Chickos and Acree, 2003) for use in converting $\Delta \mathrm{Hex}^{, \infty}$ to $\Delta \mathrm{H}_{\mathrm{Solv}}$, and vice versa.

Mintz et al. (Mintz et al., 2007; Mintz et al., 2008b; Mintz et al., 2009) and Sprunger et al. (2009a) demonstrated that the Abraham model does provide an accurate mathematical description of enthalpies of solvation of organic vapors and gases in water, $\Delta \mathrm{H}_{\mathrm{Solv}, \mathrm{W}}$,

$$
\begin{gathered}
\Delta \mathrm{H}_{\text {Solv }, \mathrm{W}}(\mathrm{kJ} / \mathrm{mole})=-13.310(0.457)+9.910(0.814) \mathrm{E}+2.836(0.807) \mathrm{S} \\
\quad-32.010(1.102) \mathrm{A}-41.816(0.781) \mathbf{B}-6.354(0.200) \mathrm{L} \\
\left(\text { with } \mathrm{N}=368, \mathrm{SD}=3.68, \mathrm{R}^{2}=0.964, \mathrm{R}^{2} \text { adj }=0.964, \mathrm{~F}=1950.5\right)
\end{gathered}
$$


and

$$
\begin{gathered}
\Delta \mathrm{H}_{\text {Solv }, \mathrm{W}}(\mathrm{kJ} / \text { mole })=-6.952(0.651)+1.415(0.770) \mathrm{E}-2.859(0.855) \mathrm{S}-34.086(1.225) \mathrm{A} \\
-42.686(0.850) \mathbf{B}-22.720(0.800) \mathrm{V} \\
\left(\text { with } \mathrm{N}=369, \mathrm{SD}=4.04, \mathrm{R}^{2}=0.959, \mathrm{R}^{2} \text { adj }=0.958, \mathrm{~F}=1688.2\right)
\end{gathered}
$$

as well as into organic solvents and ionic liquids. From a thermodynamic standpoint Eqn. 28 is the enthalpic temperature derivative of the Abraham model's gas-to-condensed phase transfer equation. Equation 29 might be more useful in some predictive applications in instances where the L-descriptor is not known. Equation 29 uses the McGowan volume, Vdescriptor, which is easily calculable from the individual atomic sizes and numbers of bonds in the molecule (Abraham and McGowan, 1987).

To provide as complete set of ion-specific equation coefficients as possible we have reanalyzed our enthalpy of solvation data for solutes dissolved in IL solvents at $323 \mathrm{~K}$ in accordance with the Eqns. 14 and 15 of the Abraham model. The derived correlations

$$
\begin{gathered}
\Delta H_{\text {solv }}=\sum_{\text {cation }}\left(c_{\text {cation }}+e_{\text {cation }} E+s_{\text {cation }} S+a_{\text {cation }} A+b_{\text {cation }} B+l_{\text {cation }} L\right)+ \\
\sum_{\text {anion }}\left(c_{\text {anion }}+e_{\text {anion }} E+s_{\text {anion }} S+a_{\text {anion }} A+b_{\text {anion }} B+l_{\text {anion }} L\right) \\
\left(\mathrm{N}=977, \mathrm{R}^{2}=0.998, \mathrm{R}_{\text {adj }}=0.998, \mathrm{SD}=1.602, \mathrm{~F}=3058\right)
\end{gathered}
$$

and

$$
\begin{gathered}
\Delta H_{\text {solv }}=\sum_{\text {cation }}\left(c_{\text {cation }}+e_{\text {cation }} E+s_{\text {cation }} S+a_{\text {cation }} A+b_{\text {cation }} B+v_{\text {cation }} V\right)+ \\
\sum_{\text {anion }}\left(c_{\text {anion }}+e_{\text {anion }} E+s_{\text {anion }} S+a_{\text {anion }} A+b_{\text {anion }} B+v_{\text {anion }} V\right) \\
\left(\mathrm{N}=977, \mathrm{R}^{2}=0.998, \mathrm{R}^{2}\right. \text { adj } \\
=0.997, \mathrm{SD}=1.655, \mathrm{~F}=2860)
\end{gathered}
$$

describe the observed enthalpy of solvation to within standard deviations of SD $=1.602$ $\mathrm{kJ} /$ mole and $\mathrm{SD}=1.655 \mathrm{~kJ} /$ mole using the ion-specific equation coefficients tabulated in Tables 5 and 6 . Standard errors in the equation coefficients are given in parenthesis immediately below the respective coefficient. For the most part, the larger standard errors were noted in the equation coefficients for those ions for which experimental data were limited. Large standard errors were similarly noted in the ion-specific equation coefficients for our initial $\log \mathrm{K}$ and $\log \mathrm{P}$ Abraham model correlations. The standard errors did decrease in magnitude when additional $\log K$ and $\log P$ values were added to the database. We expect the same to happen with the $\Delta \mathrm{H}_{\text {solv }}$ correlations.

Comparsions of experimental $\Delta \mathrm{H}_{\text {Solv }}$ data versus back-calculated values based on the two Abraham model correlations are graphically depicted in Figures 6 and 7. Each calculation uses only the values for the cation and anion in the given RTIL. For example, to predict the enthalpies of solvation of organic vapors and gases in 1-(3-hydroxypropyl)pyridinium tris(pentafluoroethyl)trifluorophosphate one would use only the six equation coefficients for the [PrOHPy $^{+}$and the six equation coefficients for the [FAP]- anion. The 13 cation-specific equation coefficients and 10 anion-specific equation coefficients listed in Tables 5 and 6 can 
be used to predict enthalpies of solvation of organic vapors and gases in 130 (13 x 10) different IL solvents. The number of ionic liquids that one can make $\Delta \mathrm{H}_{\text {solv }}$ predictions for is far smaller than the 299 ILs for which $\log \mathrm{K}$ and $\log \mathrm{P}$ predictions can be made.

Predicted values of enthalpies of solvation based on Eqns. 30 and 31 can be used to correct predicted $\log \mathrm{K}$ and $\log \mathrm{P}$ values at $298.15 \mathrm{~K}$ to other temperatures. For the $\log \mathrm{P}$ corrections one will need an experimental or predicted value for the enthalpy of solvation of the solute in water, $\Delta \mathrm{H}_{\text {Solv, }} \mathrm{W}$, as well (see Eqns. 12 and 13). The Abraham model correlation derived by Mintz et al. can be used to estimate $\Delta \mathrm{H}_{\mathrm{Solv}, \mathrm{W}}$ if an experimental value is not available. An error/uncertainty of $\pm 2 \mathrm{~kJ} /$ mole in the enthalpy of solvation results in an error of slightly less than $0.04 \log$ units in extrapolating a $\log \mathrm{K}$ value measured at $298.15 \mathrm{~K}$ to a temperature of 313.15. This level of predictive error will be sufficient for most practical chemical separation applications. For gas-liquid chromatographic separations Abraham model correlations have been reported (Breitbach and Armstrong, 2008; Anderson et al., 2002; Baltazar et al., 2008; Zhao et al., 2009) for predicting solute retention factors on a few select mono-cationic and di-cationic IL stationary phases at higher temperatures.

\begin{tabular}{|c|c|c|c|c|c|c|}
\hline Ion $^{\mathrm{a}}$ & $\mathrm{C}_{\text {ion }}$ & $\mathrm{e}_{\text {ion }}$ & $S_{\text {ion }}$ & $a_{\text {ion }}$ & $b_{\text {ion }}$ & $l_{\text {ion }}$ \\
\hline \multicolumn{7}{|l|}{ CATIONS } \\
\hline$[\mathrm{MEIm}]^{+}$ & -6.007 & 3.914 & -15.247 & -20.601 & -7.607 & -7.153 \\
\hline$(\mathrm{N}=257)^{\mathrm{b}}$ & $(0.821)$ & $(1.563)$ & $(1.749)$ & $(2.147)$ & $(1.704)$ & $(0.249)$ \\
\hline [BMIm] $^{+}$ & -6.223 & -1.307 & -8.699 & -20.815 & -9.869 & -7.072 \\
\hline$(\mathrm{N}=179)$ & $(0.642)$ & $(1.407)$ & $(1.926)$ & $(2.169)$ & $(2.328)$ & $(0.173)$ \\
\hline 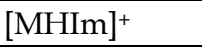 & -5.543 & 0.111 & -6.842 & -19.484 & -10.780 & -7.795 \\
\hline$(\mathrm{N}=101)$ & $(0.685)$ & $(1.577)$ & $(2.013)$ & $(2.362)$ & $(2.357)$ & $(0.187)$ \\
\hline$\left[_{\mathrm{MOIm}}\right]^{+}$ & -7.758 & 1.088 & -4.778 & -21.886 & -6.993 & -7.448 \\
\hline$(\mathrm{N}=86)$ & $(0.907)$ & $(2.153)$ & $(2.631)$ & $(2.686)$ & $(2.588)$ & $(0.274)$ \\
\hline$\left[\mathrm{M}_{3} \mathrm{BAm}\right]^{+}$ & -7.255 & 1.352 & -9.405 & -22.715 & -7.191 & -6.761 \\
\hline$(\mathrm{N}=51)$ & $(0.969)$ & $(2.041)$ & $(2.724)$ & (3.067) & $(3.151)$ & $(0.237)$ \\
\hline$\left[\mathrm{M}_{2} \mathrm{EIm}\right]^{+}$ & -0.592 & 4.122 & -15.849 & -23.339 & -7.193 & -8.667 \\
\hline$(\mathrm{N}=37)$ & $(1.570)$ & $(2.097)$ & $(2.221)$ & $(2.629)$ & $(2.015)$ & $(0.442)$ \\
\hline [4-BMPy] $^{+}$ & -2.796 & 5.802 & -19.743 & -27.272 & -2.956 & -8.378 \\
\hline$(\mathrm{N}=69)$ & $(1.127)$ & $(2.094)$ & $(2.554)$ & $(2.343)$ & $(2.210)$ & $(0.334)$ \\
\hline [3-BMPy] $^{+}$ & -6.188 & 5.800 & -18.460 & -20.302 & -2.050 & -7.565 \\
\hline$(\mathrm{N}=36)$ & $(1.992)$ & $(3.406)$ & $(4.291)$ & $(4.378)$ & $(4.375)$ & $(0.589)$ \\
\hline$\left[\mathrm{E}_{3} \mathrm{~S}\right]^{+}$ & -2.913 & 15.064 & -32.880 & -15.755 & -5.551 & -7.845 \\
\hline$(\mathrm{N}=28)$ & $(1.642)$ & $(4.601)$ & $(7.428)$ & $(10.973)$ & $(12.526)$ & $(0.495)$ \\
\hline [BMPyr] $^{+}$ & -5.800 & 10.249 & -25.046 & -16.107 & -3.629 & -7.191 \\
\hline$(\mathrm{N}=30)$ & $(1.710)$ & $(4.440)$ & $(5.683)$ & $(4.725)$ & $(4.739)$ & $(0.539)$ \\
\hline [HxomMIm] $^{+}$ & -3.748 & 13.318 & -24.942 & -27.250 & 1.260 & -8.645 \\
\hline$(\mathrm{N}=34)$ & $(1.589)$ & $(3.132)$ & $(4.019)$ & $(3.056)$ & $(3.335)$ & $(0.479)$ \\
\hline$\left[(\mathrm{Hxom})_{2} \mathrm{Im}\right]^{+}$ & -4.547 & 13.240 & -21.422 & -28.533 & 0.734 & -8.833 \\
\hline
\end{tabular}




\begin{tabular}{|c|c|c|c|c|c|c|}
\hline$(\mathrm{N}=34)$ & $(1.589)$ & $(3.132)$ & $(4.019)$ & $(3.056)$ & $(3.235)$ & $(0.479)$ \\
\hline$[\mathrm{PrOHPy}]^{+}$ & -25.941 & -15.090 & 28.322 & -15.026 & -33.898 & -2.429 \\
\hline$(\mathrm{N}=35)$ & $(2.861)$ & $(7.406)$ & $(9.520)$ & $(12.678)$ & $(11.759)$ & $(0.844)$ \\
\hline $\mathrm{ANIONS}$ & & & & & & \\
\hline$\left[(\mathrm{Tf})_{2} \mathrm{~N}^{-}\right.$ & 0.000 & 0.000 & 0.000 & 0.000 & 0.000 & 0.000 \\
\hline$(\mathrm{N}=394)$ & & & & & & \\
\hline$\left[\mathrm{BF}_{4}\right]^{-}$ & -0.520 & -3.920 & 3.391 & 1.969 & -1.162 & 0.494 \\
\hline$(\mathrm{N}=136)$ & $(0.751)$ & $(1.805)$ & $(2.224)$ & $(2.303)$ & $(2.144)$ & $(0.227)$ \\
\hline$\left[\mathrm{PF}_{6}\right]^{-}$ & -5.420 & 12.391 & -24.092 & 13.322 & 14.997 & 0.806 \\
\hline$(\mathrm{N}=54)$ & $(0.813)$ & $(2.647)$ & $(3.369)$ & $(3.463)$ & $(3.616)$ & $(0.254)$ \\
\hline$[\mathrm{EtSO}]^{-}$ & -3.021 & -2.344 & 6.454 & -16.911 & 1.412 & 1.106 \\
\hline$(\mathrm{N}=42)$ & $(1.551)$ & $(2.634)$ & $(3.036)$ & $(3.747)$ & $(3.276)$ & $(0.379)$ \\
\hline$[\mathrm{Trif}]^{-}$ & 2.171 & 2.471 & -5.152 & -19.614 & 6.577 & -0.696 \\
\hline$(\mathrm{N}=132)$ & $(1.253)$ & $(2.224)$ & $(2.796)$ & $(3.195)$ & $(3.132)$ & $(0.378)$ \\
\hline$\left[\mathrm{F}_{3} \mathrm{Ac}\right]^{-}$ & 5.481 & 9.027 & -6.060 & -12.187 & -16.266 & -1.763 \\
\hline$(\mathrm{N}=27)$ & $(1.849)$ & $(4.864)$ & $(7.649)$ & $(11.189)$ & $(12.648)$ & $(0.561)$ \\
\hline$[\mathrm{NO}]_{3}^{-}$ & -3.591 & 0.499 & -0.226 & -14.195 & 5.620 & 0.520 \\
\hline$(\mathrm{N}=28)$ & $(3.254)$ & $(2.953)$ & $(2.980)$ & $(4.528)$ & $(2.842)$ & $(0.970)$ \\
\hline$[\mathrm{SCN}]^{-}$ & 7.978 & 14.895 & -23.862 & -26.264 & 12.733 & -2.220 \\
\hline$(\mathrm{N}=84)$ & $(1.103)$ & $(2.444)$ & $(3.255)$ & $(2.689)$ & $(2.961)$ & $(0.316)$ \\
\hline$\left[\mathrm{B}(\mathrm{CN})_{4}\right]^{-}$ & 20.462 & 5.485 & -24.845 & -39.242 & 21.911 & -4.524 \\
\hline$(\mathrm{N}=22)$ & $(2.434)$ & $(7.100)$ & $(9.553)$ & $(13.453)$ & $(12.973)$ & $(0.729)$ \\
\hline$[\mathrm{FAP}]^{-}$ & 25.824 & 17.977 & -48.802 & -4.930 & 10.119 & -4.938 \\
\hline$(\mathrm{N}=58)$ & -2.405 & $(6.922)$ & $(8.926)$ & $(12.306)$ & $(11.333)$ & $(0.713)$ \\
\hline
\end{tabular}

a Cation and anion abbreviations are given in the footnote to Table 3.

${ }^{b}$ Number of experimental data points associated with the specified ion.

Table 5. Cation-Specific and Anion-Specific Equation Coefficients for the Abraham Model Enthalpy of Solvation Correlation (Eqn.30)

\begin{tabular}{|l|c|c|c|c|c|c|}
\hline Ion $^{\mathrm{a}}$ & $\mathrm{c}_{\text {ion }}$ & $\mathrm{e}_{\text {ion }}$ & $\mathrm{s}_{\text {ion }}$ & $\mathrm{a}_{\text {ion }}$ & $\mathrm{b}_{\text {ion }}$ & $\mathrm{v}_{\text {ion }}$ \\
\hline CATIONS & -0.522 & -8.710 & -15.755 & -24.770 & -7.602 & -25.280 \\
\hline${\text { [MEIm }]^{+}}_{(\mathrm{N}=257)^{\mathrm{b}}}$ & $(1.027)$ & $(1.469)$ & $(1.838)$ & $(2.270)$ & $(1.765)$ & $(0.914)$ \\
\hline$\left[_{\mathrm{BMIm}]^{+}}\right.$ & 0.671 & -10.742 & -13.978 & -23.150 & -10.347 & -26.260 \\
\hline$(\mathrm{N}=179)$ & $(0.794)$ & $(1.409)$ & $(2.004)$ & $(2.238)$ & $(2.395)$ & $(0.646)$ \\
\hline$[\mathrm{MHIm}]^{+}$ & 0.103 & -12.846 & -7.474 & -16.018 & -15.782 & -27.380 \\
\hline$(\mathrm{N}=101)$ & $(0.851)$ & $(1.584)$ & $(2.083)$ & $(2.421)$ & $(2.412)$ & $(0.697)$ \\
\hline$\left[_{\mathrm{MOIm}}^{+}\right]^{+}$ & -3.094 & -14.937 & -1.923 & -21.742 & -10.249 & -25.306 \\
\hline$(\mathrm{N}=86)$ & $(1.147)$ & $(2.122)$ & $(2.745)$ & $(2.799)$ & $(2.672)$ & $(1.021)$ \\
\hline [M $\left._{3} \mathrm{BAm}\right]^{+}$ & -1.158 & -7.091 & -15.020 & -25.483 & -6.221 & -24.671 \\
\hline
\end{tabular}




\begin{tabular}{|c|c|c|c|c|c|c|}
\hline$(\mathrm{N}=51)$ & $\begin{array}{l}(1.197) \\
\end{array}$ & $(2.059)$ & $(2.867)$ & (3.202) & $(3.259)$ & $\begin{array}{l}(0.891) \\
\end{array}$ \\
\hline$\left[\mathrm{M}_{2} \mathrm{EIm}\right]^{+}$ & 4.006 & -5.855 & -21.604 & -28.854 & -3.145 & -29.304 \\
\hline$(\mathrm{N}=37)$ & $(1.881)$ & $(1.962)$ & $(2.463)$ & $(2.829)$ & $(2.100)$ & $(1.576)$ \\
\hline [4-BMPy] $^{+}$ & 1.375 & -11.008 & -16.169 & -28.921 & -5.933 & -27.874 \\
\hline$(\mathrm{N}=69)$ & $(1.372)$ & $(2.024)$ & $(2.654)$ & $(2.454)$ & $(2.280)$ & $(1.195)$ \\
\hline${\text { [3-BMPy }]^{+}}^{+}$ & 1.324 & -6.735 & -20.274 & -23.121 & -4.582 & -28.299 \\
\hline$(\mathrm{N}=36)$ & (2.435) & (3.415) & $(4.442)$ & (4.505) & $(4.529)$ & $\begin{array}{l}(2.107) \\
\end{array}$ \\
\hline$\left[\mathrm{E}_{3} \mathrm{~S}\right]^{+}$ & 4.009 & -10.891 & -17.029 & -23.710 & -12.059 & -28.593 \\
\hline$(\mathrm{N}=28)$ & $(2.124)$ & $(4.789)$ & (7.631) & $(11.458)$ & $(12.920)$ & $(1.860)$ \\
\hline [BMPyr] $^{+}$ & 2.509 & -6.665 & -20.110 & -20.750 & -9.554 & -27.793 \\
\hline$(\mathrm{N}=30)$ & $\begin{array}{l}(2.141) \\
\end{array}$ & $(4.169)$ & (5.749) & $(4.885)$ & $(4.842)$ & $(1.961)$ \\
\hline [HxomMIm] $^{+}$ & 2.168 & -5.927 & -19.612 & -27.547 & -4.531 & -30.045 \\
\hline$(\mathrm{N}=34)$ & $(1.977)$ & $(3.112)$ & $(4.111)$ & (3.166) & (3.397) & $(1.732)$ \\
\hline$\left[(\mathrm{Hxom})_{2} \mathrm{Im}\right]^{+}$ & 1.063 & -6.379 & -15.883 & -28.570 & -5.017 & -30.303 \\
\hline$(\mathrm{N}=34)$ & $(1.977)$ & $(3.112)$ & $(4.111)$ & (3.166) & (3.397) & $(1.732)$ \\
\hline [PrOHPy $^{+}$ & -24.316 & -6.193 & 7.321 & -15.580 & -23.480 & -8.586 \\
\hline$(\mathrm{N}=35)$ & $(3.552)$ & $(8.005)$ & $(9.947)$ & (13.201) & (11.998) & $(3.057)$ \\
\hline \multicolumn{7}{|l|}{ ANIONS } \\
\hline$\left[(\mathrm{Tf})_{2} \mathrm{~N}\right]^{-}$ & 0.000 & 0.000 & 0.000 & 0.000 & 0.000 & 0.000 \\
\hline \multicolumn{7}{|l|}{$(\mathrm{N}=394)$} \\
\hline$\left[\mathrm{BF}_{4}\right]^{-}$ & 0.525 & 3.258 & -5.021 & -0.272 & 3.289 & 0.404 \\
\hline$(\mathrm{N}=136)$ & $(0.968)$ & (1.774) & $(2.346)$ & $\begin{array}{l}(2.427) \\
\end{array}$ & $(2.225)$ & $(0.862)$ \\
\hline$\left[\mathrm{PF}_{6}\right]^{-}$ & -3.055 & 14.791 & -27.034 & 9.240 & 18.214 & 0.108 \\
\hline$(\mathrm{N}=54)$ & $(1.074)$ & $(2.662)$ & (3.515) & $(3.608)$ & (3.733) & (1.006) \\
\hline$\left[\mathrm{EtSO}_{4}\right]^{-}$ & -1.724 & 5.034 & -1.145 & -17.689 & 4.040 & 2.461 \\
\hline$(\mathrm{N}=42)$ & $(1.964)$ & $(2.584)$ & $(3.309)$ & $(4.005)$ & $(3.406)$ & $(1.449)$ \\
\hline [Trif] $^{-}$ & 0.513 & -0.513 & -2.324 & -16.775 & 5.462 & -0.738 \\
\hline$(\mathrm{N}=132)$ & $(1.525)$ & $(2.158)$ & $(2.908)$ & $(3.281)$ & $(3.220)$ & $(1.340)$ \\
\hline$\left[\mathrm{F}_{3} \mathrm{Ac}\right]^{-}$ & 7.964 & -7.797 & 13.304 & -17.312 & -24.326 & -7.359 \\
\hline$(\mathrm{N}=27)$ & $(2.404)$ & $(5.003)$ & $(7.884)$ & (11.705) & $(13.049)$ & $(2.124)$ \\
\hline$\left[\mathrm{NO}_{3}\right]^{-}$ & -6.235 & 4.613 & -3.847 & -10.664 & 8.528 & 3.247 \\
\hline$(\mathrm{N}=28)$ & $(3.616)$ & $(2.622)$ & $(3.381)$ & $(4.656)$ & $(2.911)$ & $(3.178)$ \\
\hline$[\mathrm{SCN}]^{-}$ & 9.842 & 1.469 & -11.336 & -31.443 & 8.565 & -8.113 \\
\hline$(\mathrm{N}=84)$ & $(1.422)$ & $(2.512)$ & (3.355) & $(2.831)$ & $(3.130)$ & $(1.205)$ \\
\hline$\left[\mathrm{B}(\mathrm{CN})_{4}\right]^{-}$ & 23.574 & -15.339 & -4.703 & -39.309 & 10.023 & -15.787 \\
\hline$(\mathrm{N}=22)$ & (3.047) & $\begin{array}{l}(7.629) \\
\end{array}$ & (9.887) & $(14.040)$ & (13.192) & $(2.647)$ \\
\hline$[\mathrm{FAP}]^{-}$ & 29.378 & -4.429 & -27.315 & -4.750 & -3.066 & -17.347 \\
\hline$(\mathrm{N}=58)$ & $(3.001)$ & $\begin{array}{l}(7.540) \\
\end{array}$ & $(9.341)$ & $(12.818)$ & $(11.546)$ & $(2.585)$ \\
\hline
\end{tabular}

a Cation and anion abbreviations are given in the footnote to Table 3.

b Number of experimental data points associated with the specified ion.

Table 6. Cation-Specific and Anion-Specific Equation Coefficients for the Abraham Model Enthalpy of Solvation Correlation (Eqn.31) 


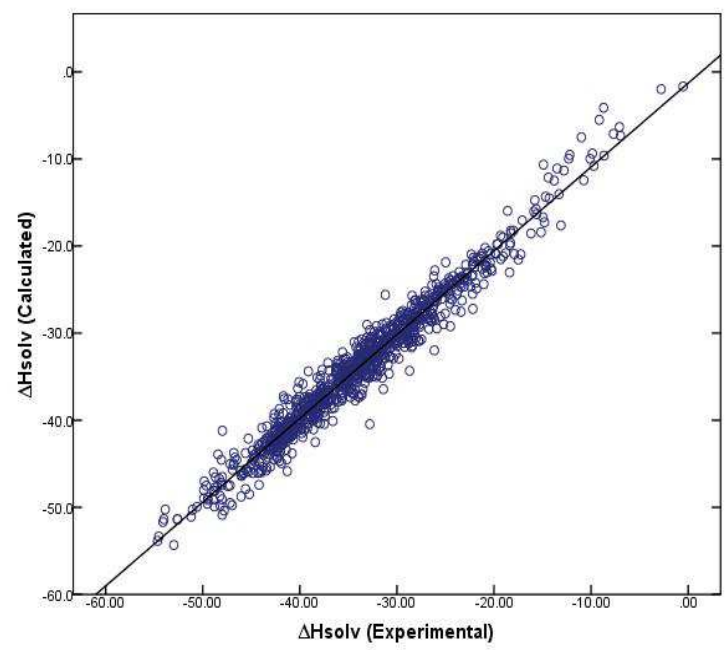

Fig. 6. Comparison between the 977 experimental $\Delta \mathrm{H}_{\text {Solv }}$ data points and predicted values based on Eqn. 30.

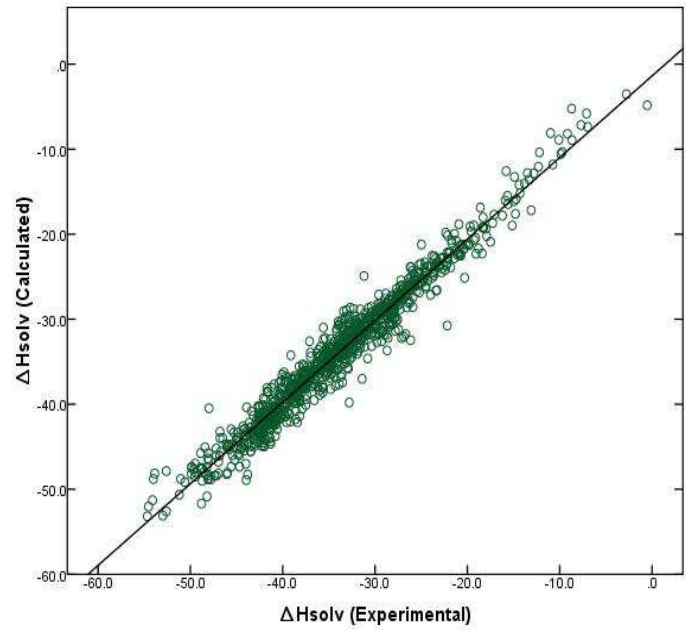

Fig. 7. Comparison between the 977 experimental $\Delta \mathrm{H}_{\text {Solv }}$ data points and predicted values based on Eqn. 31

\section{Conclusion}

The Abraham general solvation provides a reasonably accurate mathematical description of the thermodynamic properties governing the solute transfer into anhydrous ionic liquid solvents from both water and from the gas phase. Derived expressions based on the Abraham model allow one to estimate the estimate the $\log \mathrm{K}$ and $\log \mathrm{P}$ values at $298 \mathrm{~K}$ for 
many solute-IL systems based on published ion-specific equation coefficients and/or published group contribution values. Comparison of experimental versus predicted values for more than 30 IL solvents suggest that the predicted $\log \mathrm{P}$ and $\log \mathrm{K}$ values should fall within $0.15 \log$ units of the observed value in most cases. The model contains provisions for correcting the predicted $\log \mathrm{K}$ and $\log \mathrm{P}$ values to other temperatures not too far removed from $298 \mathrm{~K}$.

\section{References}

Abraham, M. H. \& McGowan, J. C. (1987) The use of characteristic volumes to measure cavity terms in reversed phase liquid chromatography. Chromatographia 23 (4) $243-$ 246.

Abraham, M. H. (1993a) Scales of solute hydrogen-bonding: their construction and application to physicochemical and biochemical processes. Chemical Society Reviews $22(2), 73-83$.

Abraham, M. H. (1993b) Application of solvation equations to chemical and biochemical processes.Pure and Applied Chemistry 65 (12), 2503-12.

Abraham, M. H.; Acree, W. E., Jr. (2006) Comparative analysis of solvation and selectivity in room temperature ionic liquids using the Abraham linear free energy relationship. Green Chemistry 8 (10), 906-915.

Abraham, M. H.; Zissimos, A. M.; Huddleston, J. G.; Willauer, H. D.; Rogers, R. D. \& Acree, W. E., Jr.(2003) Some Novel Liquid Partitioning Systems: Water-Ionic Liquids and Aqueous Biphasic Systems. Industrial E Engineering Chemistry Research 42, 413-418.

Abraham, M. H.; Ibrahim, A. \& Zissimos, A. M. (2004) Determination of sets of solute descriptors from chromatographic measurements. Journal of Chromatography, A 1037 (1-2), 29-47.

Abraham, M. H.; Ibrahim, A.; Zhao, Y.; Acree, W. E., Jr. (2006) A data base for partition of volatile organic compounds and drugs from blood/plasma/serum to brain, and an LFER analysis of the data. Journal of Pharmaceutical Sciences 95 (10), 2091-2100.

Abraham, M. H.; Ibrahim, A. \& Acree, W. E. Jr. (2007) Air to liver partition coefficients for volatile organic compounds and blood to liver partition coefficients for volatile organic compounds and drugs . European Journal of Medicinal Chemistry 42 (6), $743-$ 751.

Abraham, M. H.; Ibrahim, A. \& Acree, W. E. Jr. (2008) Air to lung partition coefficients for volatile organic compounds and blood to lung partition coefficients for volatile organic compounds and drugs. European Journal of Medicinal Chemistry 43 (3), 478485.

Abraham, M. H.; Acree, W. E., Jr. \& Cometto-Muniz, J. E. (2009) Partition of compounds from water and from air into amides. New Journal of Chemistry 33 (10), 2034-2043.

Abraham, M. H.; Smith, R. E.; Luchtefeld, R.; Boorem, A. J.; Luo, R.; Acree, W. E., Jr. (2010) Prediction of solubility of drugs and other compounds in organic solvents. Journal of Pharmaceutical Sciences 99 (3), 1500-1515.

Acree, W. E., Jr. \& Abraham, M. H. (2006) The analysis of solvation in ionic liquids and organic solvents using the Abraham linear free energy relationship. Journal of Chemical Technology and Biotechnology 81 (8), 1441-1446.

Aguilera-Herrador, E.; Lucena, R.; Cardenas, S.; Valcarcel, M. (2008) Ionic liquid-based single-drop microextraction/gas chromatographic/mass spectrometric 
determination of benzene, toluene, ethylbenzene and xylene isomers in waters. Journal of Chromatography, A 1201 (1), 106-111.

Anderson, J. L.; Ding, J.; Welton, T. \& Armstrong, D. W. (2002) Characterizing ionic liquids on the basis of multiple solvation interactions. Journal of the American Chemical Society 124 (47), 14247-14254.

Arey, J. S.; Green, W. H., Jr. \& Gschwend, P. M. (2005) The electrostatic origin of Abraham's solute polarity parameter. J. Phys. Chem. B 109, 7564-7573.

Baltazar, Q. Q.; Leininger, Suzette K.; Anderson, J. L. (2008) Binary ionic liquid mixtures as gas chromatography stationary phases for improving the separation selectivity of alcohols and aromatic compounds. Journal of Chromatography, A, 1182 (1), 119-127.

Breitbach, Z. S.; Armstrong, D. W. (2008) Characterization of phosphonium ionic liquids through a linear solvation energy relationship and their use as GLC stationary phases. Analytical and Bioanalytical Chemistry 390 (6), 1605-1617.

Chickos, James S.; Acree, William E., Jr. (2003) Enthalpies of vaporization of organic and organometallic compounds, 1880-2002. Journal of Physical and Chemical Reference Data 32 (2), 519-878.

Chickos, J. S. \& Acree, W. E., Jr. (2002) Enthalpies of sublimation of organic and organometallic compounds. 1910-2001. Journal of Physical and Chemical Reference Data 31 (2), 537-698.

Grubbs, L. M.; Saifullah,M.; De La Rosa, N. E.; Acree, W. E., Jr.; Abraham, M. H.; Zhao, Q. \& Anderson, J. L. Cation-specific and anion-specific Abraham model correlations for solute transfer into ionic liquids. Global Journal of Physical Chemistry, 1 (1), 1-19.

Lei, Z.; Li, C. \& Chen, B. (2003) Extractive distillation: a review. Separation and Purification Reviews 32 (2), 121-213.

Lei, Z.; Arlt, W.; Wasserscheid, P. (2006) Separation of 1-hexene and n-hexane with ionic liquids. Fluid Phase Equilibria, 241 (1-2), 290-299.

Liu, J.-F.; Jiang, G.-B.; Chi, Y.-G.; Cai, Y.-Q.; Zhou, Q.-X.; Hu, J.-T. (2003) Use of ionic liquids for liquid-phase micro-extraction of polycyclic aromatic hydrocarbons. Analytical Chemistry 75 (21), 5870-5876.

Mintz, C. \& Acree, W. E Jr. (2007) Partition coefficient correlations for transfer of solutes from gas phase and water to room temperature ionic liquids. Physics and Chemistry of Liquids 45 (3), 241-249.

Mintz, C.; Clark, M.; Acree, W. E., Jr. \& Abraham, M. H. (2007) Enthalpy of solvation correlations for gaseous solutes dissolved in water and in 1-octanol based on the Abraham model. Journal of Chemical Information and Modeling 47 (1), 115-121.

Mintz, C.; Ladlie, T.; Burton, K.; Clark, M.; Acree, W. E., Jr. \& Abraham, M. H. (2008a) Characterization of the partitioning of gaseous solutes into humic acid with the Abraham model and temperature-independent equation coefficients. QSAR $\mathcal{E}$ Combinatorial Science 27 (4), 483-491.

Mintz, C.; Ladlie, T.; Burton, K.; Clark, M.; Acree, W. E., Jr. \& Abraham, M. H. (2008b) Enthalpy of solvation correlations for gaseous solutes dissolved in alcohol solvents based on the Abraham model. QSAR \& Combinatorial Science, 27 (5), 627-635.

Mintz, C.; Burton, K.; Ladlie, T.; Clark, M.; Acree, W.E.; Abraham, M. H. (2009) Enthalpy of solvation correlations for organic solutes and gases dissolved in N,Ndimethylformamide and tert-butanol. Journal of Molecular Liquids 144 (1-2), 23-31. 
Mokrushin, V.; Assenbaum, D.; Paape, N.; Gerhard, D.; Mokrushina, L.; Wasserscheid, P.; Arlt, W.; Kistenmacher, H.; Neuendorf, S. \& Goeke, V. (2010) Ionic liquids for propene-propane separation. Chemical Engineering \& Technology, 33 (1), 63-73.

Mutelet, F. \& Rogalski, M. (2001) Experimental determination and prediction of the gasliquid n-hexadecane partition coefficients. J. Chromatogr., A 923, 153-163.

Mutelet, F.; Revelli, A.-L.; Jaubert, J.-N.; Sprunger, L. M.; Acree, W. E., Jr. \& Baker, G. A. (2010) Partition Coefficients of Organic Compounds in New Imidazolium and Tetralkyl-ammonium Based Ionic Liquids Using Inverse Gas Chromatography. Journal of Chemical \& Engineering Data 55 (1), 234-242.

Palgunadi, J.; Kim, H. S.; Lee, J. M. \& Jung, S. (2010) Ionic liquids for acetylene and ethylene separation: Material selection and solubility investigation. Chemical Engineering and Processing 49 (2), 192-198.

Pandey, S. (2006) Analytical applications of room-temperature ionic liquids: A review of recent efforts. Analytica Chimica Acta 556 (1), 38-45.

Pereiro, A. B.; Deive, F. J.; Esperança, J. M. M. S. \& Rodríguez, A. (2010) Alkylsulfate-based ionic liquids to separate azeotropic mixtures. Fluid Phase Equilibr., 291 (1), 13-17.

Pharma Algorithms, (2006) ADME Boxes, Version 3.0; Pharma Algorithms Inc.: Toronto, Ontario, Canada, 2006.

Planeta, J. \& Roth, M. (2005) Solute Partitioning between the Ionic Liquid 1-n-Butyl-3methylimidazolium Tetrafluoroborate and Supercritical CO2 from CapillaryColumn Chromatography. Journal of Physical Chemistry B 109 (31), 15165-15171.

Planeta, J.; Karasek, P. \& Roth, M (2007) Limiting partition coefficients of solutes in biphasic trihexyltetradecyl-phosphonium chloride ionic liquid-supercritical CO2 system: measurement and LSER-based correlation. Journal of Physical Chemistry B 111 (26), 7620-7625.

Planeta, J.; Karasek, P. \& Roth, M. (2009) Distribution of organic solutes in biphasic 1-nbutyl-3-methylimidazolium methyl sulfate-supercritical CO2 system. Journal of Physical Chemistry B, 113 (28), 9520-9526.

Platts, J. A.; Butina, D.; Abraham, M. H.; Hersey, A. (1999) Estimation of molecular linear free energy relation descriptors using a group contribution approach. J. Chem. Inf. Comput. Sci. 1999, 39, 835-845.

Poole, C. F. \& Poole, Salwa K. (2010) Extraction of organic compounds with room temperature ionic liquids. Journal of Chromatography, A 1217(16), 2268-2286.

Proctor, A. Sprunger, L. M.; Acree, W. E., Jr.; Abraham, M. H. (2008) LFER correlations for the solubilising characterisation of room temperature ionic liquids containing trifluoromethanesulfonate and trifluoroacetate anions. Physics and Chemistry of Liquids 46 (6), 631-642.

Revelli, A.-L.; Sprunger, L. M.; Gibbs, J.; Acree, W. E.; Baker, G. A. \& Mutelet, F. (2009) Activity coefficients at infinite dilution of organic compounds in trihexyl(tetradecyl)phosphonium bis(trifluoromethylsulfonyl)imide using inverse gas chromatography. Journal of Chemical and Engineering Data 54 (3), 977-985.

Revelli, A.-L.; Mutelet, F. \& Jaubert, J.-N. (2010a) Prediction of partition coefficients of organic compounds in ionic liquids: use of a linear solvation energy relationship with parameters calculated through a group contribution method. Industrial $\mathcal{E}$ Engineering Chemistry Research 49 (8), 3883-3892. 
Revelli, A.-L.; Mutelet, F.; Jaubert, J.-N.; Garcia-Martinez, M.; Sprunger, L. M.; Acree, W. E., Jr. \& Baker, Gary A. (2010b) Study of ether-, alcohol-, or cyano-functionalized ionic liquids using inverse gas chromatography. Journal of Chemical \& Engineering Data, 55 (7), 2434-2443.

Roth, M. (2009) Partitioning behaviour of organic compounds between ionic liquids and supercritical fluids. Journal of Chromatography, A 1216 (10), 1861-1880.

Seeley, J. V.; Seeley, S. K.; Libby, E. K.; Breitbach, Z. S. \& Armstrong, D. W. (2008) Comprehensive two-dimensional gas chromatography using a high-temperature phosphonium ionic liquid column. Analytical and Chemistry 390(1), 323-332.

Soukup-Hein, R. J.; Warnke, M. M. \& Armstrong, D. W. (2009) Ionic liquids in analytical chemistry. Annual Review of Analytical Chemistry 2, 145-168.

Sprunger L.; Acree W. E., Jr. \& Abraham M. H. (2007a) Linear free energy relationship correlation of the distribution of solutes between water and sodium dodecyl sulfate (SDS) micelles and between gas and SDS micelles. Journal of Chemical Information and Modeling 47 (5), 1808-17.

Sprunger, L.; Clark, M.; Acree, W. E., Jr. \& Abraham, M. H. (2007b) Characterization of room-temperature ionic liquids by the Abraham model with cation-specific and anion-specific equation coefficients. Journal of Chemical Information and Modeling 47 (3), 1123-1129.

Sprunger, L.; Proctor, A.; Acree, W. E. Jr. \& Abraham, M. H. (2007c) Characterization of the sorption of gaseous and organic solutes onto polydimethyl siloxane solid-phase microextraction surfaces using the Abraham model. Journal of Chromatography, A 1175 (2), 162-173.

Sprunger, L. M.; Proctor, A.; Acree, W. E., Jr. \& Abraham, M. H. (2008) LFER correlations for room temperature ionic liquids: Separation of equation coefficients into individual cation-specific and anion-specific contributions. Fluid Phase Equilibria 265 (1-2), 104-111.

Sprunger, L. M.; Achi, S. S.; Acree, W. E. \& Abraham, M. H. (2009a) Linear Free Energy Relationship Correlations for Enthalpies of Solvation of Organic Solutes into RoomTemperature Ionic Liquids Based on the Abraham Model with Ion-Specific Equation Coefficients.. Industrial and Engineering Chemistry Research 48 (18), 87048709.

Sprunger, L. M.; Gibbs, J.; Baltazar, Q. Q.; Acree, W. E., Jr.; Abraham, M. H.; Anderson, J. L. (2009b) Characterisation of room temperature ionic liquid chromatographic stationary phases by combining experimental retention factor and partition coefficient data into a single model. Physics and Chemistry of Liquids 47 (1), 74-83.

Sprunger, L. M.; Gibbs, J.; Proctor, A.; Acree, W. E., Jr.; Abraham, M. H.; Meng, Y.; Yao, C. \& Anderson, J. L. (2009c) Linear free energy relationship correlations for room temperature ionic liquids: revised cation-specific and anion-specific equation coefficients for predictive applications covering a much larger area of chemical space. Industrial and Engineering Chemistry Research 48 (8), 4145-4154.

Verma, V. K. \& Banerjee, T. (2010) Ionic liquids as entrainers for water+ethanol, water+2propanol, and water+THF systems: A quantum chemical approach. Journal of Chemical Thermodynamics 42 (7), 909-919.

Yao, C.; Pitner, W. R. \& Anderson, J. L. (2009) Ionic liquids containing the tris(pentafluoroethyl)trifluorophosphate anion: a new class of highly selective and 
ultra hydrophobic solvents for the extraction of polycyclic aromatic hydrocarbons using single drop microextraction. Analytical Chemistry 81 (12), 5054-5063.

Zhao, Q.; Eichhorn, J.; Pitner, W. R. \& Anderson, J. L. (2009) Using the solvation parameter model to characterize functionalized ionic liquids containing the tris(pentafluoroethyl)trifluorophosphate (FAP) anion. Analytical and Bioanalytical Chemistry 395 (1), 225-234.

Zhao, F.-Q.; Li, J.; Zeng, B.-Z. (2008) Coupling of ionic liquid-based headspace single-drop microextraction with GC for sensitive detection of phenols. Journal of Separation Science 31 (16-17), 3045-3049.

Zhao, F.; Lu, S.; Du, W. \& Zeng, B. (2009) Ionic liquid-based headspace single-drop microextraction coupled to gas chromatography for the determination of chlorobenzene derivatives. Microchimica Acta 165(1-2), 29-33.

Zhu, J.; Chen, J. \& Fei, W. (2004) Separation of aromatic hydrocarbons or olefins from paraffins using new ionic liquids. Huagong Xuebao (Chinese Edition), 55, 2091-2094.

Zissimos, A. M.; Abraham, M. H.; Barker, M. C.; Box, K. J.; Tam, K. Y. (2002a) Calculation of Abraham descriptors from solvent-water partition coefficients in four different systems; evaluation of different methods of calculation. Journal of the Chemical Society, Perkin Transactions 2 (3), 470-477.

Zissimos, A. M.; Abraham, M. H.; Du, C. M.; Valko, K.; Bevan, C.; Reynolds, D.; Wood, J.; Tam, K. Y. (2002b) Calculation of Abraham descriptors from experimental data from seven HPLC systems; evaluation of five different methods of calculation. Journal of the Chemical Society, Perkin Transactions 2 (12), 2001-2010. 


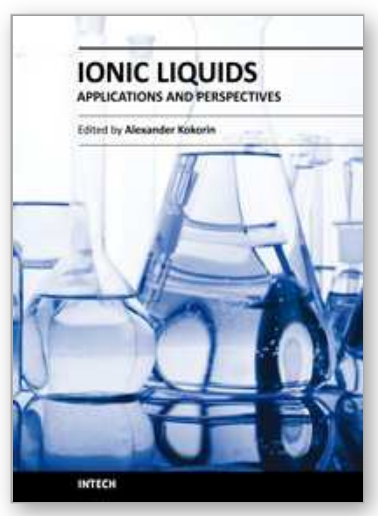

\author{
Ionic Liquids: Applications and Perspectives \\ Edited by Prof. Alexander Kokorin
}

ISBN 978-953-307-248-7

Hard cover, 674 pages

Publisher InTech

Published online 21, February, 2011

Published in print edition February, 2011

This book is the second in the series of publications in this field by this publisher, and contains a number of latest research developments on ionic liquids (ILs). This promising new area has received a lot of attention during the last 20 years. Readers will find 30 chapters collected in 6 sections on recent applications of ILs in polymer sciences, material chemistry, catalysis, nanotechnology, biotechnology and electrochemical applications. The authors of each chapter are scientists and technologists from different countries with strong expertise in their respective fields. You will be able to perceive a trend analysis and examine recent developments in different areas of ILs chemistry and technologies. The book should help in systematization of knowledges in ILs science, creation of new approaches in this field and further promotion of ILs technologies for the future.

\title{
How to reference
}

In order to correctly reference this scholarly work, feel free to copy and paste the following:

William E. Acree, Jr., Laura M. Grubbs and Michael H. Abraham (2011). Selection of Ionic Liquid Solvents for Chemical Separations Based on the Abraham Model, lonic Liquids: Applications and Perspectives, Prof. Alexander Kokorin (Ed.), ISBN: 978-953-307-248-7, InTech, Available from: http://www.intechopen.com/books/ionic-liquids-applications-and-perspectives/selection-of-ionic-liquid-solventsfor-chemical-separations-based-on-the-abraham-model

\section{INTECH}

open science | open minds

\section{InTech Europe}

University Campus STeP Ri

Slavka Krautzeka 83/A

51000 Rijeka, Croatia

Phone: +385 (51) 770447

Fax: +385 (51) 686166

www.intechopen.com

\section{InTech China}

Unit 405, Office Block, Hotel Equatorial Shanghai

No.65, Yan An Road (West), Shanghai, 200040, China

中国上海市延安西路65号上海国际贵都大饭店办公楼 405 单元

Phone: +86-21-62489820

Fax: $+86-21-62489821$ 
(C) 2011 The Author(s). Licensee IntechOpen. This chapter is distributed under the terms of the Creative Commons Attribution-NonCommercialShareAlike-3.0 License, which permits use, distribution and reproduction for non-commercial purposes, provided the original is properly cited and derivative works building on this content are distributed under the same license. 